Using mark-recapture methods to estimate population size and survival of pyjama sharks (Poroderma africanum) in Mossel Bay, South Africa

\author{
Samantha P. Grusd
}

Supervisors: Dr. Enrico Gennari (Oceans Research)

Coleen Moloney (UCT)

Greg Distiller (UCT)

Minor dissertation submitted to the University of Cape Town in partial fulfillment of the requirements for the degree of Master of Science in Applied Marine Science

\author{
Department of Biological Sciences \\ University of Cape Town \\ Rondebosch, Cape Town \\ South Africa 7701
}

March 2017 
The copyright of this thesis vests in the author. No quotation from it or information derived from it is to be published without full acknowledgement of the source. The thesis is to be used for private study or noncommercial research purposes only.

Published by the University of Cape Town (UCT) in terms of the non-exclusive license granted to UCT by the author. 


\section{Dedication and Acknowledgements}

I would like to give thanks to my supervisors Dr. Enrico Gennari (Oceans Research), A/P Coleen Moloney (University of Cape Town) and Greg Distiller (University of Cape Town) for their ongoing support and encouragement while completing my M.Sc.

Thank you to the scientists at Oceans Research in Mossel Bay for allowing me to utilize their various recapture datasets for this study and for all of their work and effort put into collecting the data and preparing the datasets for me. Thanks to the science faculty, staff and fellow students at UCT for encouraging me to always try my hardest and helping me realize that my hard work and dedication will pay off in the end.

Lastly, I want to give thanks to my friends near and far and to my brother Jake who always support me and are there for me no matter what, and a special thank you to my parents who have continued to support me, financially and emotionally, throughout my entire educational career and for always encouraging me to pursue my dreams.

This thesis is thereby dedicated to all of my friends, family and supervisors who have helped me, encouraged me and inspired me to pursue my dreams and continue to work in this field. 


\section{Table of Contents}

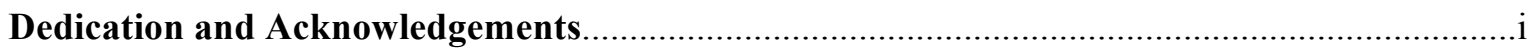

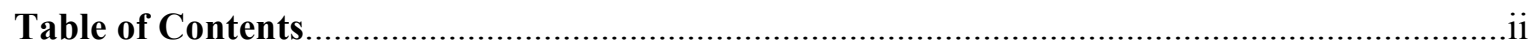

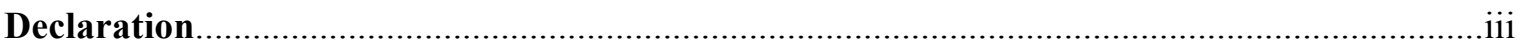

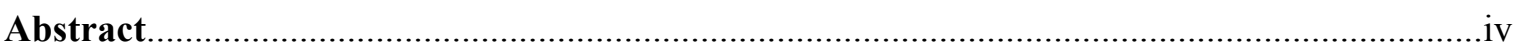

Introduction and Literature Review........................................................................

1.1 Scyliorhinidae.

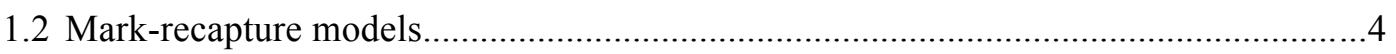

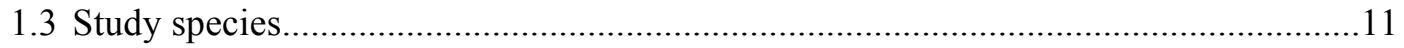

Methods.

2.1 Study site

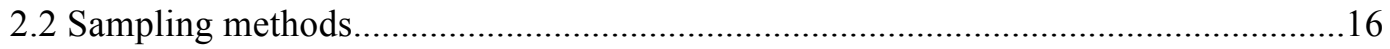

2.2.1 Conventional tagging ...........................................................................16

2.2.2 Passive acoustic telemetry .....................................................................17

2.3 Model descriptions and construction.................................................................18

2.3.1 Model assumptions: Pollock's robust design...............................................18

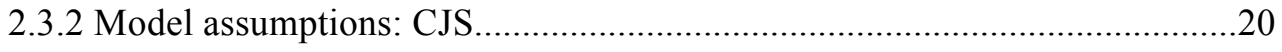

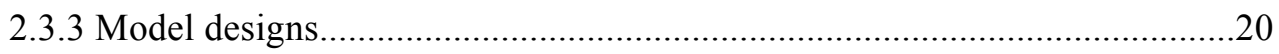

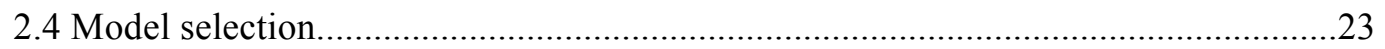

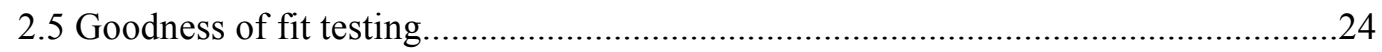

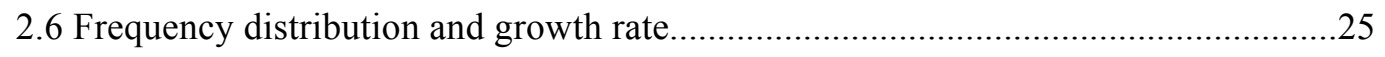

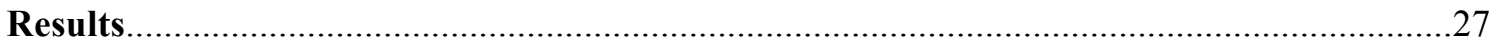

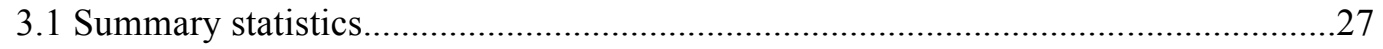

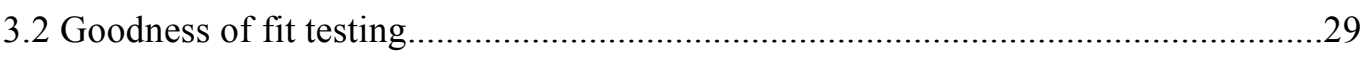

3.3 Robust design estimates (conventional tag data): abundance, temporary emigration and capture probability.........................................................................

3.4 CJS estimates (acoustic tag data): apparent survival and capture probability.............31

3.5 Growth curve

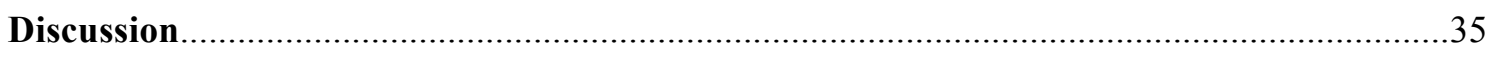

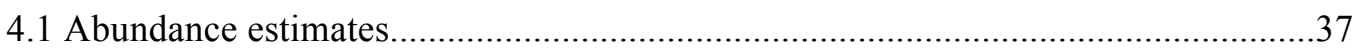

4.2 Apparent survival estimates and capture probabilities..............................................39

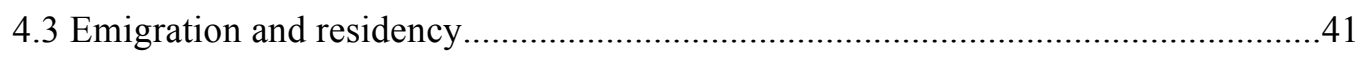

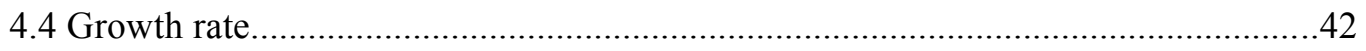

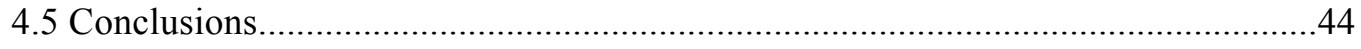

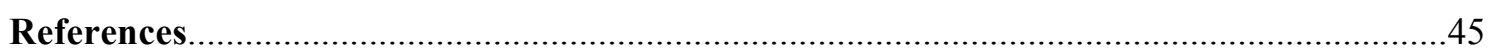

Appendix A

Grusd, S.P. 2017 


\section{Declaration}

I, Samantha P. Grusd, hereby declare that the work on which this thesis is based is my original work (except where acknowledgements indicate otherwise) and that neither the whole work nor any part of it has been, is being, or is to be submitted for another degree in this or any other university. Furthermore, I authorize the University of Cape Town to reproduce, for the purpose of research, either the whole or any portion of the contents of this thesis in any manner whatsoever.

\section{Signed by candidate}

Signature Removed

Signature:

Date: 20, June 2017 


\section{Abstract}

Sharks are vulnerable to exploitation as a result of their biological characteristics. Markrecapture models were applied to conventional tag recapture data and acoustic telemetry data to estimate abundance, apparent survival, recapture probability and temporary emigration for the pyjama shark, Poroderma africanum in Mossel Bay, South Africa over a five-year period. This study applied Pollock's robust design (with the conventional tag data) and Cormack-Jolly-Seber (CJS) models (with the acoustic tag data) to analyze the mark-recapture data. In addition, a von Bertalanffy model was fit to the data to estimate individual growth. The best-fit robust design model showed the population as having no temporary emigration, survival probability that is dependent on the length at first capture, and time-constant capture probabilities. The best-fit CJS model showed the population also having time-constant survival, but sex dependent capture probabilities. Robust design abundance estimates (with 95\% C.I.) in Mossel Bay varied from 279 (102-787) sharks to 733 (320-1777) sharks, although confidence intervals were quite large. CJS apparent annual survival (95\% C.I.; CJS) was estimated to be 0.254 year $^{-1}(0.04$ to 0.56$)$ and annual recapture probability $\left(95 \%\right.$ C.I.) was estimated to be 0.008 year $^{-1}(0.003-0.20)$, indicating that survival and recaptures for this endemic species are relatively low. Annual somatic growth rate $(\mathrm{k})$ was estimated to be 0.213 year $^{-1}$, indicating that this population is slow growing, a characteristic common in most shark species. Overall, the results in this study provide baseline knowledge on this population in Mossel Bay and can be used to implement proper management techniques. This knowledge can be further expanded upon to give a more in-depth understanding of all size and age classes in the population and the role that the environment and anthropogenic activities play in the population structure. 


\section{Introduction and Literature Review}

Members of the subclass Elasmobranchii (sharks and batoids (skates and rays)) can be characterized as possessing a cartilaginous skeleton, dermal denticles on the external surface, and five to seven gill slits (Compagno 1999; Heemstra and Heemstra 2004). Elasmobranchs comprise roughly 1100 species worldwide; sharks alone make up about 500 of these species (Compagno 2001; Heemstra and Heemstra 2004). Sharks occupy a wide range of habitats, from shallow coastal waters to depths up to $4000 \mathrm{~m}$ (Heemstra and Heemstra 2004). Shark populations are vulnerable to exploitation as a result of their characteristic slow growth rate, relatively late maturity, low fecundity, and in some cases their spatial characteristics, such as site fidelity and endemism (Stevens et al. 2000; Heupel and Bennett 2007; Schaub and Abadi 2011). Site fidelity is the tendency of an animal to return to a previously occupied site or sites (Switzer 1993; Speed et al. 2010) and is commonly displayed by species that exhibit limited dispersal (Isik 2011; Bond et al. 2012), where endemism refers to a species that is found in only one geographic region of large (e.g. continental or national endemism) or small (e.g. local or regional endemism) size (Isik 2011).

Sharks are top predators and are usually at or near the top of the food chain, making them important ecosystem regulators (Stevens et al. 2000; Musick and Bonfil 2005). The removal of sharks from an ecosystem can cause a cascading effect down the food chain, or a collapse in the food chain (Musick and Bonfil 2005), thereby influencing the ecosystem structure and function. As a result of their slow growth rates and late maturity, once these vulnerable species are exploited, it could take decades for them to recover (Stevens et al. 2000; Coelho 2007). In contrast, many teleosts (bony fish), which exhibit early maturity, high fecundity and are shorter- 
lived, are able to bounce back and tolerate a wider range of fishing pressures (Best et al. 2013). However, survival into adulthood is reduced in highly fecund teleosts compared to the less fecund elasmobranchs (Moyle and Cech Jr. 2004).

\subsection{Scyliorhinidae}

Scyliorhinidae (catsharks) is one of the largest families of sharks worldwide (115 known species and about 36 undescribed species) and a diverse group in southern Africa, with at least eleven endemic species. Despite this, little is known about their biology, distribution and population trends (Heemstra and Heemstra 2004; Ebert et al. 2006; Human 2006). Sharks in the family Scyliorhinidae are classified as bottom dwellers with dorsal fins that lack spines, where the first dorsal fin begins relatively far back (over or behind the pelvic fin); the presence of an anal fin; five gill slits, where the fifth gill slit is located above or behind the pectoral fin base; small multicuspid teeth; and nasal barbels (Bass et al. 1975; Compagno 2005; Escobar-Porras and Mann 2013). Because of their unique fin shape and positioning, Scyliorhinids are known to be weak swimmers, therefore they are thought to not migrate long distances (i.e. they are resident species; Springer 1979; Heemstra and Heemstra 2004). Furthermore, Scyliorhinids in South Africa are generally found on (or near) the bottom and are confined to the cold, shallow benthic environments of the south and southwest coasts. However, some species have been seen in depths near $2000 \mathrm{~m}$ (Heemstra and Heemstra 2004). The high degree of endemism can be attributed to the warmer, subtropical conditions at the outer limits of their distribution range acting as the barrier to their distribution (Heemstra and Heemstra 2004). 
While there have only been few studies conducted on the growth and population trends of sharks in family Scyliorhinidae, studies have been conducted on other elasmobranch species that exhibit similar life history characteristics (e.g. slow growth, late maturity and low fecundity). For example, the lesser spotted dogfish (Scyliorhinus canicula, family Scyliorhinidae) was used as an indicator of exploitation along the coasts of Europe. This species is vulnerable to fishing pressure because of its slow growth, late maturity and low fecundity (Massutí and Moranta 2003; Bendiab et al. 2012). Bendiab et al. (2012) calculated a somatic (body) growth rate (k) of $0.57 \mathrm{y}^{-1}$ for both sexes for this population, and found that length at maturity was longer in individuals caught in the North Atlantic than those caught in the Mediterranean Sea $(520-600 \mathrm{~mm}$ vs. $370-470 \mathrm{~mm}$, respectively). This suggests that growth and reproductive parameters of S. canicula differ between regions, potentially because of environmental influences and latitudinal differences (Bendiab et al. 2012).

Another study, conducted by Rinelli et al. (2005), on the distribution and biology of the blackmouth catshark (Galeus melastomus, family Scyliorhinidae) in the southern Tyrrhenian Sea found that all life stages were observed in both spring and autumn. However, the total catch consisted of predominantly immature individuals (first stage). This species was also predominantly caught in the deepest waters $(500-800 \mathrm{~m})$, where there was a significant increase in mean length with increasing depth; mean length of G. melastomus caught at $200 \mathrm{~m}-500 \mathrm{~m}$ was $213.4 \mathrm{~mm}$ for females and $192.7 \mathrm{~mm}$ for males, and at $500 \mathrm{~m}-800 \mathrm{~m}$ was $282.5 \mathrm{~mm}$ for females and 296.2mm for males (Rinelli et al. 2005). Although mature individuals represented a small portion of the total catch, females with eggs were observed in both spring and autumn, suggesting that this species has a wide reproductive period (Rinelli et al. 2005). 


\subsection{Mark-recapture models}

A key process that is used to assess the population growth or decline in many marine species is the use of population models. Mark-recapture models are commonly used for population estimates of marine species as they can account for varying distribution patterns, environmental influences and life history characteristics of the species of interest (Lebreton et al. 1992; Pine et al. 2003; Smith et al. 2013; White et al. 2015). Mark-recapture models are useful tools that can be used to estimate population size (N; abundance) and survival (S) of marked animals in the population of interest from data obtained through multiple sampling occasions, and thus can be used to establish the status and size of the population (Lettink and Armstrong 2003; Lettink 2012; Smith et al. 2013). However, apparent survival ( $\varphi$; the probability that an animal is alive and available for recapture in the study area) is commonly estimated, rather than true survival (S), as true survival is estimated from dead recovery data (Cooch and White 2006). A population can be defined as a group of animals (of the same species) residing in a distinct area at a specific time (Williams et al. 2002a). Population size is the quantity of individuals of that species within the population area at that specific time (Williams et al. 2002a). Population size can be conditional on climate, the resources available and environmental influences (both natural and anthropogenic; Schaub and Abadi 2011). The estimates obtained through mark-recapture models provide insight into how the population could be reacting to threats (e.g. climate change, fishing pressure) and where further research is needed in order to understand the population dynamics (the changes in the population size and structure over time; Lettink and Armstrong 2003; Schaub and Abadi 2011). Changes in population size and structure are often a response to ecosystem 
alterations, whether they are natural disturbances (e.g. climate change) or anthropogenic manipulations (e.g. fishing pressure, pollution; Stevens et al. 2000; Anderson et al. 2004; Schaub and Abadi 2011) thus, it is important to understand the population dynamics of an ecosystem. Furthermore, understanding changes in the population can allow for insight into their causes (e.g. fishing pressure, habitat destruction, changes in temperature, etc.) and for effective management to take place (Lee at al. 2014). Mark-recapture models are useful as they are able to account for influences on detection probability, including: (1) trap shyness, when an animal that has been previously captured learns over time to avoid the capture gear; this is common in areas where multiple capture occasions occur with the same gear (White et al. 2015); (2) not capturing an animal that is present in the population; and (3) other behavioral characteristics. Models that account for behavioral characteristics in the capture probability imply that an individual's behavior is modified after first capture (Otis et al. 1978). This means that all unmarked individuals have one capture probability and all marked individuals have another capture probability, and the capture probabilities do not vary with time (trapping session; Otis et al. 1978).

When conducting a mark-recapture study, the first step is to identify the type of model to use (e.g. open population model or closed population model) based on the population that is being worked on and the objectives of the study (i.e. is it long-term or short-term). An open population means that additions (e.g. births, immigration) and losses (e.g. deaths, emigration) to the population can occur during the study period. This is usually for longer-term studies (months, years; Pollock et al. 1990). A closed population assumes there are no additions or losses to the population during the study period and is useful for shorter-term studies (days, weeks, months; Pollock et al. 1990). Once models are fit to the data, model selection tools are used to assess and 
select the model that best fits the data (Cooch and White 2006). The most commonly used model selection tool is Akaike's Information Criterion with a correction for small sample sizes (AICc). AICc is an unbiased method that estimates the predicted Kullback-Leibler (K-L) information distance for the mark-recapture models and chooses the model with the lowest expected K-L information distance as the best-fit model (Posada and Buckley 2004). The K-L information distance represents how close a model is to the truth, where the model with the lowest K-L distance is the truest model. Hence the model with the lowest AICc represents the model of best fit (Bozdogan 1987; Burnham and Anderson 2002; Posada and Buckley 2004). AICc is represented by the equation:

$$
\mathrm{AICc}=-2 l+2 K+\frac{(2 K+1)}{(n-K-1)}
$$

Where $l$ is the log-likelihood, $K$ is the number of estimable parameters and $n$ is the sample size (Posada and Buckley 2004).

Although many studies have been done that have applied mark-recapture models to characterize the population dynamics of pelagic shark species, for which there is more recapture information available, there is limited information about the population dynamics of many benthic shark species, as these species can be difficult to study (Heupel and Bennett 2007). Heupel and Bennett (2007) estimated the population abundance of the epaulette shark (Hemiscyllium ocellatum), a benthic species endemic to Australia and New Guinea, on Heron Island Reef using mark-recapture methods. This species is an important ecosystem regulator on the reef, as they are the main predator of many invertebrate species (Heupel and Bennett 2007). They tagged 496 sharks with external dart tags and recorded sex and size measurements. Both 
open and closed mark-recapture models were used to estimate abundance $(\mathrm{N}) ; \mathrm{N}$ was estimated to be $1814-2249$ sharks from the closed model and $\mathrm{N}=553-1905$ sharks from the open population model. Data indicated a high recapture rate for the available population (Heupel and Bennett 2007), suggesting that the obtained sample method is representative of the whole population on Heron Island Reef and that the population could be resident within the study area, thus indicating high site fidelity. Results showed that epaulette sharks are abundant on Heron Island Reef, highlighting their importance as an ecosystem regulator on the reef (Heupel and Bennett 2007). The closed population estimates were originally preferred, as epaulette sharks are a resident species, however, data indicated that the epaulette sharks did move out of the study site (but not off of the reef). Thus Heupel and Bennett (2007) concluded that this population is "partially open", hence the open population estimates were deemed more realistic than the closed population estimates. Furthermore, it was a three-year study and assuming closure over a threeyear period is incorrect and violates the assumptions of closed population models that no births, deaths, immigration or emigration occur during the sample periods (Pollock et al. 1990).

In contrast to Heupel and Bennett (2007), who only used recapture data (conventional tag and release only), many studies have proposed using combined datasets. This involves combining different types of data such as movement (acoustic telemetry) data and conventional capture-recapture data. Doing so will result in more precise population estimates, as it will allow for estimation of parameters that are not possible to obtain using only one type of dataset (Abadi et al. 2010; Schaub and Abadi 2011; Lee et al. 2014; Dudgeon et al. 2015). Acoustic telemetry involves recording the presence of individuals that are tagged with internal acoustic transmitters within the study area through mounted acoustic receivers (Heupel et al. 2006). Using multiple methods to obtain a dataset allows for linkage of a wide range of parameters and covariates, 
which may not be obtainable from one method alone (Schaub and Abadi 2011). For example, with acoustic telemetry data, the length of the animal tagged is only recorded during initial capture when the tag is implanted (the rest of the data come from the animal passing by the acoustic receiver). With conventional recapture data, the length of the animal is recorded each time it is captured; this allows for growth to be analyzed. Additionally, acoustic telemetry data more precisely reveal the distribution of animals within the study area and often result in greater resighting rates than those obtained through conventional tag and release methods (Heupel et al. 2006), thus increasing the precision of the data used for population estimates. Dudgeon et al. (2015) compared estimates of population abundance and apparent survival of the broadnose sevengill shark (Notorhynchus cepedianus) calculated from acoustic telemetry data and longline (conventional recapture) data separately to the estimates calculated from the combined acoustic tag and conventional recapture datasets. They used open population Cormack-Jolly-Seber (CJS; used to estimate apparent survival) and Jolly-Seber (JS; used to estimate abundance) models for data obtained over a three-year period. Results showed a relatively low recapture rate for the longline data; eight out of 25 acoustically tagged sharks were recorded on the receivers in the study area during the fishing period, but only two of those acoustically tagged sharks were recaptured on the longline. Furthermore, low longline recapture rates resulted in low precision in the estimates. Hence longline (conventional recapture) data alone has the potential to produce uncertain population estimates if not carried out properly, depending on the species. The estimates from the acoustic telemetry data combined with the longline data showed much higher precision $($ abundance $(N)=563-1246$ sharks; apparent annual survival $(\varphi)=0.7595-0.9332$ year $^{-1} ; \mathrm{CV}(\%)$ of $\left.\mathrm{N}=12.2-12.7\right)$ than the estimates from the longline data alone $(\mathrm{N}=439-1088$ sharks; $\varphi=0.8740-0.9838$ year $^{-1} ; \mathrm{CV}(\%)$ of $\mathrm{N}=49.5-54.7$; Dudgeon et al. 2015). Overall, 
combining acoustic telemetry data with conventional recapture data allows for improved precision in the population estimates, and therefore gives the best insight to the status of the population.

Another widely used mark-recapture model, which allows for more "robust" population estimates, is Pollock's robust design (Pollock 1981). The robust design is a widely used model to estimate population size, as it accounts for the fact that many species exhibit temporary emigration into or out of the population (Pollock 1981; Smith et al. 2013). The robust design is a combination of the open population CJS model and closed capture models, thus it can estimate parameters that could not be estimated by an open or closed population model alone (Pollock 1982; Williams et al. 2002b; Smith et al. 2013). The method consists of primary sampling periods (e.g. years), which are assumed to be the open periods, and a number of secondary sampling periods (e.g. weeks, months) within each primary period, which are closed (Pollock 1982; Lettink and Armstrong 2003; Lettink 2012). The idea is that the population size can be estimated within each primary sampling period by assuming that the population remains constant during the secondary periods (Pollock et al. 1990). Furthermore, survival rates and the number of additions or losses to the population can be estimated between primary periods (Pollock et al. 1990).

Smith et al. (2013) used the robust design to estimate seasonal abundance and demographic parameters of coastal bottlenose dolphins (Tursiops spp.) in Australia. In their three-year study, the primary periods were seasons, with 11 primary periods throughout the study, and a total of 54 secondary sampling periods (survey sessions) that occurred within the primary periods. The number of secondary periods varied for each primary period as a result of unexpected weather restrictions. Thus they chose the robust design, as it was a three-year study 
and this method allowed for flexibility in the sampling occasions and in the intervals between sampling occasions (Smith et al. 2013). Dorsal fin photo-identification was used to distinguish individuals, as is done in most delphinid species, where the initial identification of an individual is the 'capture' and the resight of that individual is the 'recapture' (Smith at al. 2013). A number of models were fit to the data with survival, capture-recapture and temporary emigration parameters modeled as time-dependent and time-constant, and where emigration was modeled as Markovian (movement into the study area is dependent on the shark's condition in the previous period), random (movement into the study area is independent on its condition in the previous period), or none (Cooch and White 2006; Smith et al. 2013). The best-fit model, as chosen per AICc, included Markovian temporary emigration as well as time-dependent survival, capture and recapture probabilities. Results indicated that the mean bottlenose dolphin abundance varied with season ( $\mathrm{N}$ ranged from 63 dolphins (95\% C.I. 69-73) in winter 2007 to 139 dolphins (95\% C.I. 134-148) in autumn 2009; Smith et al. 2013). The change in seasonal abundance could arise from the mating patterns typical of bottlenose dolphins, where males have a larger home range (lower site fidelity) than females, and tend to return to the females during the breeding season (summer/autumn; Smith et al. 2013). They concluded that the robust design was an appropriate method for evaluating abundance and apparent survival of this migratory species as it allowed accommodation for their intricate life-history characteristics (Smith et al. 2013).

Overall, the robust design allows for a more biologically realistic evaluation of population dynamics by accounting for many life history characteristics of the species of interest that other open or closed models alone could not achieve (Williams et al. 2002b; Smith et al. 2013). Therefore the robust design is a suitable model choice for this study to estimate abundance over time. 


\subsection{Study species}

The pyjama shark, Poroderma africanum, is a benthic shark species belonging to the family Scyliorhinidae and endemic to the coast of South Africa, from Saldanha Bay to East London (Fig. 1; Bass et al. 1975; Heemstra and Heemstra 2004; Escobar-Porras and Mann 2013). A keyidentifying feature is the three to five dark longitudinal stripes extending from the head to the tail (Springer 1979; Heemstra and Heemstra 2004). Although most Elasmobranch species are vulnerable to local fishing pressure and changes in the environment, the pyjama shark, being a coastal species and a weak swimmer, is further restricted in their ability to respond to these changes, as a result of their limited distribution (Anderson et al. 2004; Skarbek 2008; Harry et al. 2011; Dr. Enrico Gennari, personal communication 2017).

Pyjama sharks are nocturnal and generally reside within the shallow intertidal up to depths of about 100m. They occupy crevices or caves during the daytime and become more active during the nighttime (Bass et al. 1975; Heemstra and Heemstra 2004). Pyjama sharks are oviparous, producing one egg per oviduct. The number of eggs laid annually is currently unknown, but this species is thought to reproduce all year round (Escobar-Porras and Mann 2013). In captivity, egg cases hatched after five months, and are thought to be on the same time scale in the wild, although this has not yet been observed (Compagno 2005). The size at hatching (both sexes) is approximately $140 \mathrm{~mm}$. Males reach adolescence between 580 and $760 \mathrm{~mm}$ and maturity between 780 and $810 \mathrm{~mm}$, whereas females reach adolescence between 650 and $720 \mathrm{~mm}$ and maturity between 790 and $830 \mathrm{~mm}$ total length (TL). Maximum size for both sexes is approximately $1000 \mathrm{~mm}$ TL and maturity is reached in both sexes at 10 to 13 years (Bass et al. 
1975, Compagno 2005; Escobar-Porras and Mann 2013). Thus, pyjama sharks exhibit the characteristic late maturity that is displayed in most elasmobranch species (Stevens et al. 2000). Dainty (2002) conducted a population study on endemic catsharks in the southwestern Cape, the western end of the total distribution range. Based on vertebral analysis over all size classes, the study concluded that the pyjama shark, Poroderma africanum, reaches $50 \%$ maturity at $824 \mathrm{~mm}$ and 24 years old, with a growth rate of 0.036 year $^{-1}$ in this area. However, population studies on this species in the Southern Cape (e.g. Mossel Bay) have not yet been conducted. As seen in Bendiab et al. (2012)'s study, the growth and reproductive characteristics of Scyliorhinid species can differ between different regions within their distribution range as a result of environmental influences, thus it is necessary to conduct a study on and understand the population structure of P. africanum in Mossel Bay, the southern region (center) of their distribution range (Fig. 1).

The population status of pyjama sharks is currently unknown in Mossel Bay, South Africa (Compagno 2005). Pyjama sharks primarily feed on crustaceans, small bony fish, cephalopods and polychaetes (Bass et al. 1975; Heemsrta and Heemstra 2004; Escobar-Porras and Mann 2013), As predators, they potentially play a role in maintaining the ecosystem dynamics in Mossel Bay. Poroderma africanum is not a target of commercial fisheries, but is often caught as bycatch in commercial fisheries in general and by recreational fishers in Mossel Bay (Compagno 2005). Population studies of this species will allow any changes to be identified as well as possible causes of the changes. Understanding the population trends and characteristics of $P$. africanum in Mossel Bay should give insight to their vulnerability to influences such as fishing pressures and climate change, and potential management measures that may be needed to maintain the population for years to come. Mossel Bay is within the center of distribution of the species (Fig. 1). A few studies have been conducted towards the western 
end of their distribution, in the Atlantic Ocean, but no studies have been done on Poroderma africanum in the center and eastern end of their distribution, in the Indian Ocean. The Indian Ocean typically is warmer than the Atlantic Ocean due to the warm Agulhas current flowing southward in this area; upwelling in the Benguela region brings cold water to the surface on the Atlantic side of South Africa (Gordon, 1988). This study will complement previous studies by focusing on Poroderma africanum in Mossel Bay (Indian Ocean) and comparing the biological, behavioral and demographic parameters to those found on the Atlantic coast, the western region of their distribution range.

The aim of this study is to estimate population size, growth and demographic characteristics of the P. africanum population in a large coastal embayment Mossel Bay, South Africa by using mark-recapture models that incorporate data obtained through acoustic telemetry receivers and conventional capture-recapture tagging methods over a five-year period. Conventional tagging, the use of external tags, is widely used to gather information on movement, stock identification, abundance, growth rate and behavior in many marine and terrestrial species (McFarlane et al. 1997). In this study, the conventional tag data were used as a method to identify as many individual sharks in the population as possible and assess any recaptures of individuals at various locations within Mossel Bay. Additionally, since these sharks were sized at initial capture and at recapture, these data were used to evaluate the somatic growth rate of this species. Passive acoustic telemetry, the use of internal acoustic transmitters, is a rising method to observe long-term migration patterns, habitat use, and home ranges for tagged animals within the detection range of the transmitters (Heupel et al. 2006). Identifying the objectives of the study is crucial for selecting the placement of the acoustic receivers. This study focuses on evaluating the pyjama shark population within Mossel Bay, thus the acoustic tagging 
data were used to analyze the home range of this species in this area (i.e. are the tagged sharks staying in one area within Mossel Bay, or in many areas across the bay).

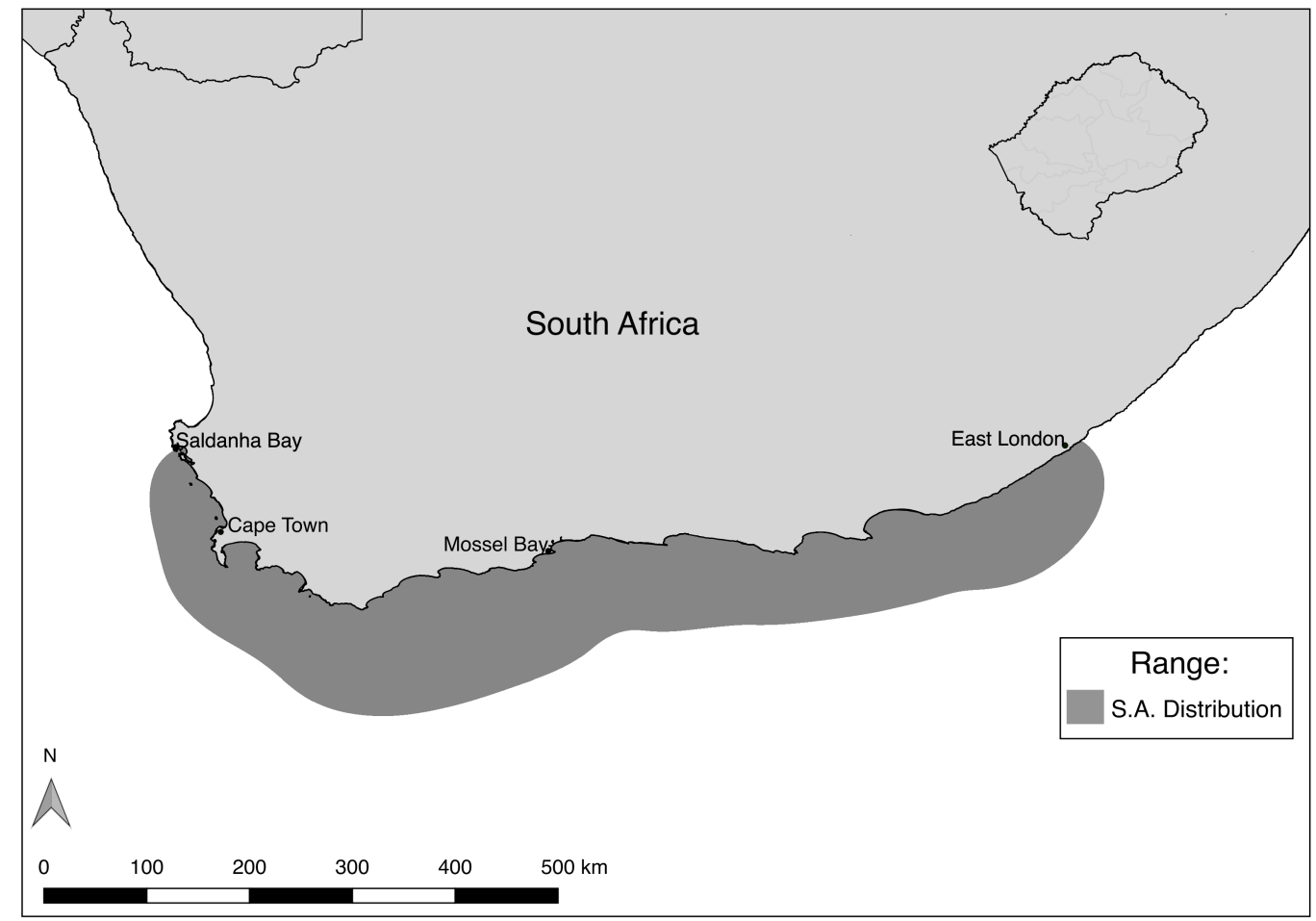

Figure 1: Distribution map of Poroderma africanum in South Africa. Created using QGIS. 


\section{Methods}

\subsection{Study site}

The fieldwork for this study took place in Mossel Bay, South Africa. Mossel Bay $\left(34.17^{\circ} \mathrm{S}\right.$, $22.08^{\circ} \mathrm{E}$ ) is located in the Western Cape province on the south west coast of South Africa, 384 $\mathrm{km}$ east of Cape Town (Fig. 2). It is a semi-sheltered bay protected from prevailing winds (Jewell et al. 2013) and is home to a wide range and diversity of marine life. It is relatively shallow and is composed of rocky reefs and sandy substrates (Fig. 2; Ryklief et al. 2014). Three rivers, Hartenbos, Klein Brak and Groot Brak, discharge into the Bay.

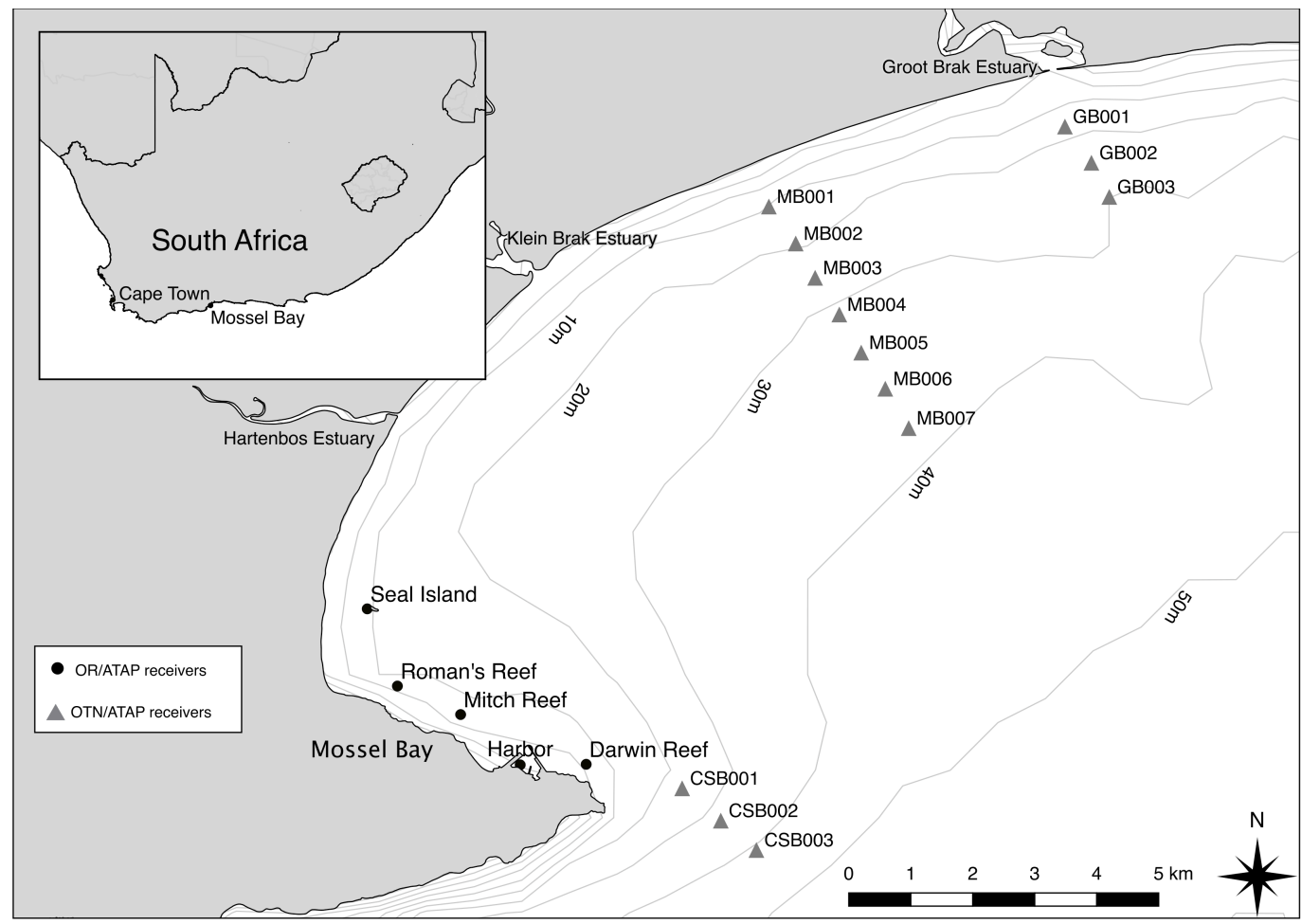

Figure 2: Map of the study area, Mossel Bay, South Africa, including the bathymetry, the locations of the five acoustic receivers implemented by Oceans Research (black circles), as well as the 13 OTN receivers (grey triangles). Depth contours indicate that the study area is relatively shallow and ranges from $10 \mathrm{~m}$ to 50m. OR = Oceans Research, OTN = Ocean Tracking Network, ATAP = Acoustic Tracking Array Platform. 


\subsection{Sampling methods}

Recapture and resight data were collected through conventional tag and release methods and passive acoustic telemetry methods, respectively. Recapture data were obtained through the traditional tagging sampling approach, using ORI tags, where the sampling periods consist of capturing individuals and marking them. However, the repeated captures have potential to cause disturbance to the animals (Cooch and White 2006). Resight data, which refers to recording the presence of an animal without physical interaction, is obtained through a "less invasive" approach where the sampling periods are sighting surveys and allows the animals to "be observed from a distance", thus minimizing disturbance (Cooch and White 2006). In this study, the term 'resight' refers to an acoustically tagged animal being detected by a receiver (Fig. 2). The data for this study were collected in advance by Oceans Research in Mossel Bay. This study used the data with their permission. The conventional recapture data were obtained through trapping and hand-lines at various locations around Mossel Bay, and the acoustic telemetry data were recorded from multiple acoustic receivers set up within Mossel Bay (Fig. 2).

\subsubsection{Conventional tagging}

The recapture data were obtained using baited traps or hand-lines at various locations around Mossel Bay. The sharks were sized to the nearest millimeter (total length- TL), tagged intramuscularly below the dorsal fin with an external conventional tag (ORI spaghetti tag) using an applicator tool (a hollow tube with a pointed end and handgrip), and released at the site of 
capture. The long yellow portion of the tag protrudes from the skin and the tag ID number is visible from the outside. No tag loss was reported.

When a pyjama shark was captured in the trap or on the hand-line and already had a spaghetti tag inserted, it was considered a recapture. For all recaptures, the date, location and size of the shark were recorded and the shark was released safely.

Sampling occurred on an average of once per week from September 2012 through July 2016. The sex of the sharks was not recorded for the conventional tagging data. The tagging reports were sent to ORI (Oceanographic Research Institute) for their database and followed their standard spreadsheet.

\subsubsection{Passive acoustic telemetry}

Multiple passive acoustic receivers (VEMCO VR2W, $69 \mathrm{kHz}$ ) were placed at various locations within Mossel Bay (Fig. 2). Each receiver was placed on a fixed mooring that stood approximately $1 \mathrm{~m}$ off the bottom and was held down by an $80 \mathrm{~kg}$ cement block. The receivers were deployed and replaced by means of SCUBA diving. The detection range of the receivers was assessed to be around $350-500 \mathrm{~m}$, mainly depending on sea conditions.

Eight pyjama sharks were tagged with internal acoustic transmitters (VEMCO V16-4H, 69KHz; power output: $158 \mathrm{~dB}$; code space: A69-9001; battery life: 1018 days; nominal delay: 90 seconds; Vemco 2014; Webber 2009) at various locations within Mossel Bay (Fig. 2; Appendix A, Table A.1). The sharks were caught, sized (TL, mm), sexed and then placed into a plastic tub where they were anaesthetized. The V16-4H acoustic transmitters were surgically implanted into the abdominal cavity by making a small incision $(2-3 \mathrm{~cm})$ along the body midline between the 
pectoral and pelvic fins. Once the tag was inserted, the incision was sutured and the shark released safely back into the water, once the anaesthetic wore off; the sharks were placed in a tub of fresh sea water to recover while the anaesthetic wore off.

The acoustic transmitters transmit a series of ultrasonic pings (signals) when they are within range of a receiver. The receiver then translates and stores the codes until the receiver is retrieved (Webber 2009). The receivers were programmed to record the ID number of the transmitter detected, as well as the date and time of detection. Acoustic monitoring occurred from October 2015 through October 2016.

\subsection{Model descriptions and construction}

Pollock's robust design (Pollock 1981) was used to analyze the conventional tag data and estimate abundance, apparent survival and capture probabilities. Cormack-Jolly-Seber (CJS) models were used to analyze apparent survival from one year of acoustic telemetry data. These estimates were then compared to the apparent survival estimates obtained from the robust design method (conventional tag data).

\subsubsection{Model assumptions: Pollock's robust design}

The robust design is a combination of both open and closed population models, therefore it combines the assumptions of both. The robust design (Fig. 3) assumes that (1) the population is open between primary periods, meaning that births, deaths, immigration and emigration can occur during these periods, and (2) that the population is closed within the primary periods (i.e. 
the secondary periods), meaning that neither additions nor losses occur during these periods (Williams et al. 2002b; Smith et al. 2013; Lee et al. 2014). The robust design, similarly to many capture-recapture models, assumes that all animals in the population have the same probability of being captured; this is the equal catchability assumption, or homogenous capture probability. However, this is unrealistic in most wildlife populations (Pollock 1981; Pollock 1982; Pollock et al. 1990). As a consequence, and because the robust design combines open and closed population models, there are two general alternative assumptions that allow for a more biologically realistic evaluation of the population. These are that (1) there is heterogeneity of capture probabilities, meaning that capture probabilities can vary with respect to size, age, sex, social status, or other factors, and (2) there is trap related response, where the capture probability is dependent on an animal's previous capture history, therefore becoming 'trap happy' with a higher recapture probability, or 'trap shy' with a lower recapture probability (Pollock 1981; Pollock 1982; Pollock et al. 1990; Smith et al. 2013).

The robust design (Fig. 3) estimates apparent survival $\left(\varphi_{i}\right)$, the probability that an individual of the population survives from time $(i)$ to time $(i+1)$, and temporary emigration (through two parameters, $\gamma_{i}{ }^{\prime}$ and $\gamma_{i}{ }^{\prime}$ ) between primary periods (Williams et al. 2002b; Smith et al. 2013). $\gamma_{i}^{\prime \prime}$ is the probability that an animal will be away from the study area, thus not available for capture, given that it was present in the study area during the previous sample period $(i-1) \cdot \gamma_{i}^{\prime}$ is the probability that an animal will be away from study area (not available for capture) given that it was not present during the previous sample period (Cooch and White 2006; Smith et al. 2013; Lee et al. 2014). Within the secondary periods, the probability of first capture $\left(\mathrm{p}_{\mathrm{ik}}\right)$, probability of recapture $\left(\mathrm{c}_{\mathrm{ik}}\right)$ and the population size in the sampling area $\left(\mathrm{N}_{i}\right)$ are estimated (Cooch and White 2006; Smith et al. 2013). The Robust design was used to estimate apparent 
survival, temporary emigration, capture probability and abundance of $P$. africanum in Mossel Bay from five years of conventional tagging data.

\subsubsection{Model assumptions: CJS}

Cormack-Jolly-Seber (CJS) open population models were used to provide robust estimates of the apparent survival $(\varphi)$ and recapture probabilities (p) of pyjama sharks in Mossel Bay from one year of acoustic telemetry data. These estimates are linked to the method, hence different but comparable estimates are expected to those from the conventional recapture data (robust design model). Similarly to the primary periods of the robust design, CJS assumes that the population is open to births, deaths, immigration and emigration (Williams et al. 2002b; Smith et al. 2013; Lee et al. 2014). An equal catchability assumption is also assumed for this method. Furthermore, it is assumed that all animals have the same probability of survival from time $(i)$ to time $(i+1)$ (Cooch and White 2006).

\subsubsection{Model designs}

RMark version 2.2.0, the $\mathrm{R}$ interface to program MARK, was used to model the data using the robust design and CJS methods. For the robust design analysis (conventional tagging data) there are five primary periods (years) and a total of 32 secondary periods (months), where the secondary periods occur within the primary periods (Fig. 3). Capture and recapture information for months January through March were excluded from this study in order to allow sufficient time between the secondary and primary periods. Additionally, sampling effort was low during 
these months. Survival was reported for the mean total length (TL; 836.2mm), the lower quartile TL (the median TL for the lower half of the dataset; 770mm) and the upper quartile TL (the median TL for the upper half of the dataset; 915mm) of P. africanum in Mossel Bay. The robust design used the beta slope and intercept estimates $\left(\beta_{1}\right.$ and $\left.\beta_{0}\right)$, which are estimates from the linear model that are calculated on the logit scale, along with the 'inv.logit ( $\beta_{0}+\beta_{1} * \mathrm{TL}_{\text {mean,lower,upper }}$ ') equation in $\mathrm{R}$ to produce these survival estimates. The default estimate from the robust design output is for the mean TL. The 'inv.logit' equation was then used to calculate it for the upper and lower quartile TLs. For the CJS analysis (acoustic tagging data), weekly capture histories were used, rather than monthly capture histories, as resightings were considerably more frequent. The survival estimates were then converted from weekly to annual estimates by multiplying it to the power of 52 ( 52 weeks in a year; e.g. $\left.\mathrm{X}^{52}\right)$. The raw capture history data can be seen in Appendix A, Table A.2 and Table A.3. 


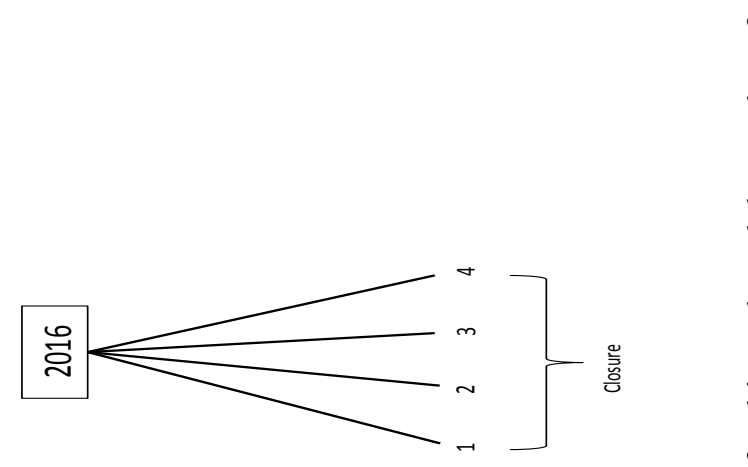

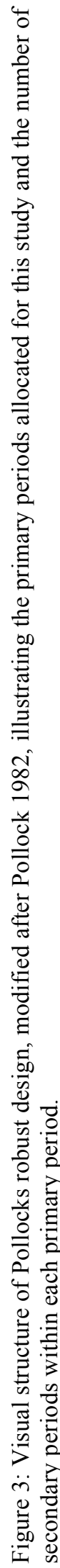

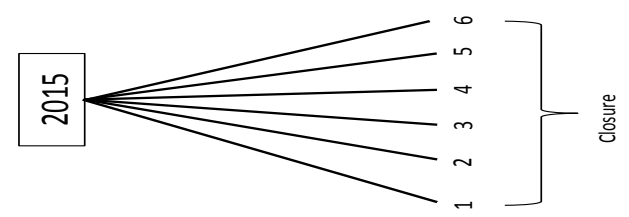

Grusd, S.P. 2017 


\subsection{Model selection}

Thirty-six reasonable models were constructed (Appendix A, Table A.4) for the robust design analysis and fifteen were constructed for the CJS analysis (Appendix A, Table A.5). Based on the known biology and life history characteristics of pyjama sharks, the parameters of the robust design models were modeled as follows: (1) apparent survival $(\varphi)$ was modeled as time-dependent $\left(\varphi_{t}\right.$; i.e. $\varphi$ changes from year to year), as TL-dependent ( $\varphi_{\mathrm{TL}}$; i.e. $\varphi$ remains fixed over time, but it is dependent on the length at first capture), as time- and TL- dependent $\left(\varphi_{t}+\mathrm{TL}\right.$; i.e. $\varphi$ changes from year to year and it is dependent on the length at first capture, but time and TL are independent of each other) and as time-constant ( $\varphi$.; i.e. $\varphi$ remains fixed (unchanged) over time); (2) temporary emigration $\left(\gamma_{i}^{\prime \prime}, \gamma_{i}^{\prime}\right)$ was modeled as Markovian (constrain gammas as $\gamma_{i}^{\prime \prime}=\gamma_{i-1}^{\prime \prime}$ and $\gamma_{i}^{\prime}=\gamma_{i-1}^{\prime}$; i.e. the probability that a shark moves into the study area between periods $i$ and $i+1$ is dependent on its condition in the previous period $(i-1)$ ), as random (constrain gamma parameters as $\gamma_{i}{ }_{i}=\gamma_{i}$; i.e. the probability that a shark moves into the study area between periods $i$ and $i+1$ is independent of its condition in the previous period $(i-1)$ ) and as having no emigration (constrain gamma parameters as $\gamma^{\prime}=0$ and $\gamma^{\prime \prime}=$ 0 ; i.e. no movement); and (3) the probability of capture (p) was set equal to the probability of recapture (c) as there was no evidence that either was influenced by tagging activities (Wisniewski et al. 2015). $\mathrm{p}=\mathrm{c}$ was modeled as time-dependent $\left(\mathrm{p}_{\text {session }}=\mathrm{c}_{\text {session }}\right.$; i.e. where session indicates that it varies by primary periods, so it changes from year to year), as season-dependent ( $\mathrm{p}_{\text {season }}=\mathrm{c}_{\text {season }}$; i.e. $\mathrm{p}$ remains unchanged over time, but is different depending on what season it is) and as time-constant ( $p .=$ c.; i.e. $p$ remains fixed (unchanged) over time; Cooch and White 2006; Lee et al. 2014; detailed in Appendix A, Table A.4). 
For the CJS analysis, $\varphi$ was modeled as time-constant $\left(\varphi\right.$.), time-dependent $\left(\varphi_{t}\right)$, and as TLdependent $\left(\varphi_{\mathrm{TL}}\right)$. $\mathrm{p}$ was modeled as time-dependent $\left(\mathrm{p}_{\mathrm{t}}\right)$, as time-constant $(\mathrm{p}$.$) , as sex-dependent \left(\mathrm{p}_{\text {sex }}\right.$; i.e. $p$ is dependent on the sex of the shark, but remains unchanged over time), as TL-dependent ( $\left.\mathrm{p}_{\mathrm{TL}}\right)$, as TL-sex dependent ( $\mathrm{p}_{\mathrm{TL}} *$ sex; i.e. $\mathrm{p}$ is dependent on the length at first capture, which is dependent on the sex of the shark, but remains unchanged over time), as TL- and sex- dependent $\left(\mathrm{p}_{\mathrm{TL}}+\right.$ sex; ; ie. $\mathrm{p}$ is dependent on the length of first capture and on the sex of the shark, but they are independent of each other, and it remains unchanged over time $)$ and as time- and sex- dependent $\left(\mathrm{p}_{\mathrm{t}+\text { sex }}\right.$; i.e. $\mathrm{p}$ changes over time and is dependent on the sex of the shark; detailed in Appendix A, Table A.5).

The best model structure was chosen based on the adjusted Akaike's Information Criterion for small sample sizes (AICc), where the model with the smallest AICc value was considered the model with the best fit.

\subsection{Goodness of fit testing}

Goodness of fit (GOF) testing is fundamental to assess the underlying assumptions of the candidate models and infer that the most general model appropriately fits the data (Cooch and White 2006). Program RELEASE is conventional for assessing the fit of the data to a fully time-dependent (general) CJS model, and was run in RMark with the function 'release.gof' (Cooch and White 2006). RELEASE adapts a chi-squared contingency table approach to estimate a chi-squared $\left(\chi^{2}\right)$ statistic, degrees of freedom (d.f.) and the p-value (significance of the test; i.e. significance indicates lack of fit; Cooch and White 2006; Tolley et al. 2010). If the data adequately fit the general model, then no adjustments need to be made (e.g. to c-hat, the variance inflation factor used to quantify over- and under-dispersion; Cooch and White 2006). 
Presently, there is no specific GOF test for the robust design. Accordingly, since robust design models do share assumptions with the CJS models, it is common practice to pool the robust design secondary period data and treat it as a CJS model to run GOF analyses (Tolley et al. 2010), as was done in this study.

The GOF of both the acoustic telemetry (used for CJS analysis) and conventional recapture (used for robust design analysis) datasets was assessed using the RELEASE GOF method, with the secondary occasion data being pooled for the conventional tag dataset.

\subsection{Frequency distribution and growth rate}

$\mathrm{R}$ version 3.2.3 and RStudio version 0.99.467 were used to construct a size-frequency distribution of the sample population (conventional tag data) and perform a Mann Whitney $U$ test, testing the null hypothesis that male pyjama shark sightings are equal to female pyjama shark sightings (from the acoustic telemetry data). A Mann Whitney $U$ test was chosen, as the sample size is quite small ( $n=$ seven sharks; three female and four male).

A growth curve for pyjama sharks was constructed based on the below von Bertalanffy growth (VBG) equation modified by Fabens (1965) for recapture data (conventional tag data) and used to first estimate growth rate, $\mathrm{k}$ :

$$
\mathrm{L}_{\mathrm{r}}=\mathrm{L}_{\infty}-\left(\mathrm{L}_{\infty}-\mathrm{L}_{\mathrm{c}}\right) * \mathrm{e}^{-\mathrm{k}_{*} \mathrm{~d}}
$$

where ' $\mathrm{L}_{\mathrm{r}}$ ' is the length at recapture, ' $\mathrm{L}_{\infty}$ ' is asymptotic length, ' $\mathrm{L}_{\mathrm{c}}$ ' is length at capture (or at first recapture), ' $\mathrm{k}$ ' is the growth rate per year $(0<\mathrm{k}<1)$ and ' $\mathrm{d}$ ' is time in years between capture (or first 
recapture) and (second) recapture. Since $\mathrm{L}_{\infty}$ is unknown for pyjama sharks, a rule of thumb for asymptotic length, suggested by Pauly (1984) was used:

$$
\mathrm{L}_{\infty} \approx \mathrm{L}_{\max } / 0.95
$$

where ' $\mathrm{L}_{\max }$ ' is the maximum length recorded in the population of interest (Froese and Binohlan 2000; Matthews and Samuel 1990).

The standard von Bertalanffy equation (Fabens 1965; Bjorndal et al. 1995; Musick and Bonfil 2005) was then used to solve for $b$ and then to plot the curve.

$$
\mathrm{L}_{\mathrm{t}}=\mathrm{L}_{\infty} *\left(1-\mathrm{b} * \mathrm{e}^{-\mathrm{k}_{*} \mathrm{t}}\right)
$$

where: ' $\mathrm{L}_{\mathrm{t}}$ ' is the length at age $t$, ' $\mathrm{t}$ ' is age in years, ' $\mathrm{L}_{\infty}$ ' is asymptotic length, ' $\mathrm{k}$ ' is the rate (per year) at which $\mathrm{L}_{\infty}$ is approached, ' $\mathrm{b}$ ' is a parameter related to size at birth; $b$ is a dimensional number equal to:

$$
\mathrm{b}=\left(\mathrm{L}_{\infty}-\mathrm{L}_{0}\right) / \mathrm{L}_{\infty}
$$

where ' $\mathrm{L}_{0}$ ' is the size at birth and ' $\mathrm{L}_{\infty}$ ' and ' $\mathrm{k}$ ' are as stated previously. Because size at birth $(\mathrm{t}=0)$ was known for P. africanum (140mm), it was used in equation (4) to solve for ' $\mathrm{b}$ '. This gave $\mathrm{b}=0.88$ year ${ }^{-1}$. 


\section{Results}

A total of 137 wild $P$. africanum was tagged with conventional spaghetti tags and eight with acoustic transmitters over the course of the study. The acoustically tagged sharks were caught during the sampling periods in the 2015 primary period (Fig. 3), while the conventionally tagged sharks were caught throughout all periods during the study (Fig. 3). However data from only 123 of the spaghetti tagged sharks and seven (four male, three female) of the acoustically tagged sharks were used in this study, as the other 14 conventionally tagged sharks and one acoustically tagged shark contained insufficient data. Insufficient data refers to sharks where no TL was recorded, sharks that were not encountered at all during the study periods (i.e. the months where they were encountered were excluded from the study to reduce violation of the assumptions), or sharks that were not resighted (detected on the acoustic receivers) after initial tagging; only one out of the eight acoustically tagged sharks was never detected after initial tagging.

\subsection{Summary statistics}

The size of pyjama sharks in the sample ranged from $570 \mathrm{~mm}$ to $1050 \mathrm{~mm}$ TL; the mean TL for the sample was $838.8 \mathrm{~mm}$ (Fig. 4; from both conventional and acoustic tag data). From the acoustic telemetry data, although the patterns of male and female sighting frequency are different (Fig. 5), the sighting frequency (i.e. detection by the acoustic receivers; Fig. 6) does not significantly differ between males and females (Mann Whitney $U$ test; $\mathrm{W}=10, \mathrm{n}_{\text {male }}=4, \mathrm{n}_{\text {female }}=3, \mathrm{p}=0.229$ ). 


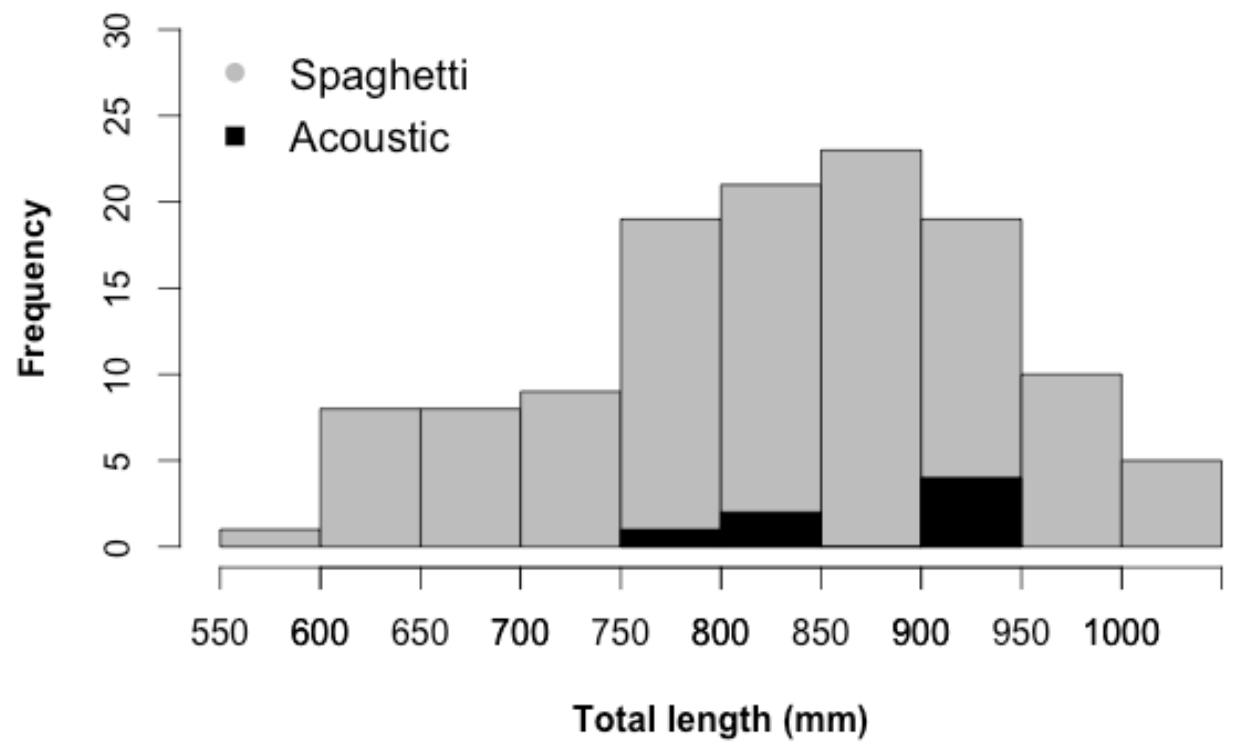

Figure 4: Length-frequency distribution for the length at first capture of Poroderma africanum caught and tagged with conventional (spaghetti) tags or acoustic transmitters in Mossel Bay from September 2012 to October 2016, showing a normal distribution.

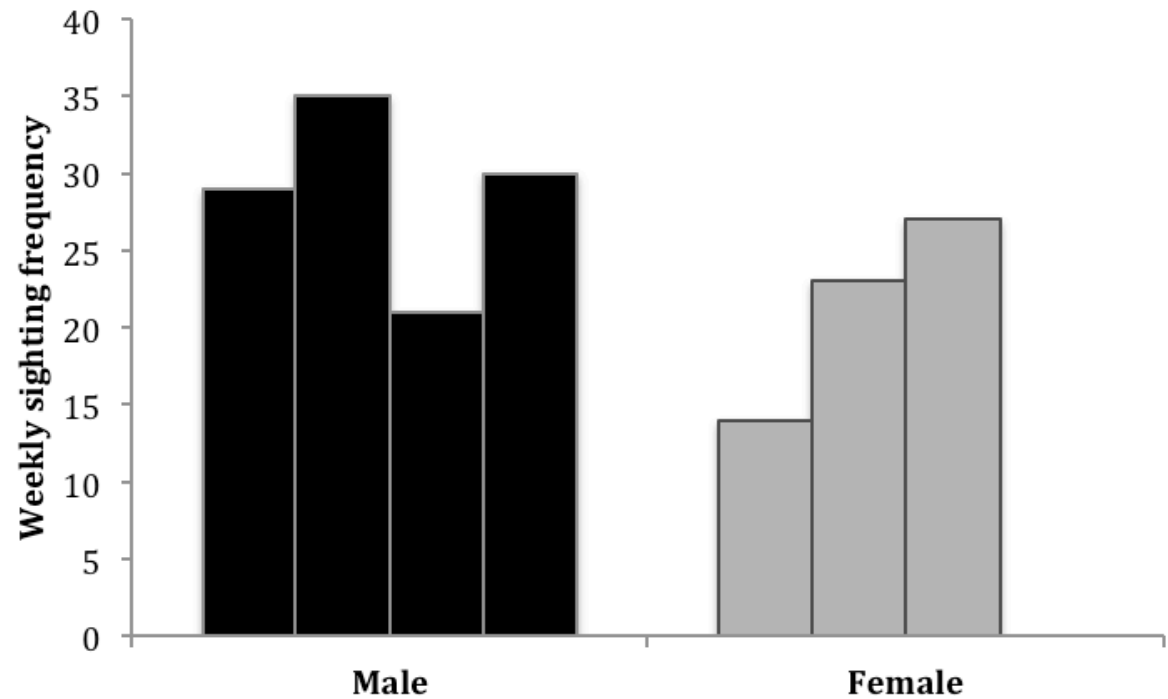

Figure 5: Weekly sighting frequency for the seven acoustically tagged $P$. africanum at various locations in Mossel Bay from October 2015 through October 2016. Each bar represents an individual shark (seven sharks total; four male, three female). 


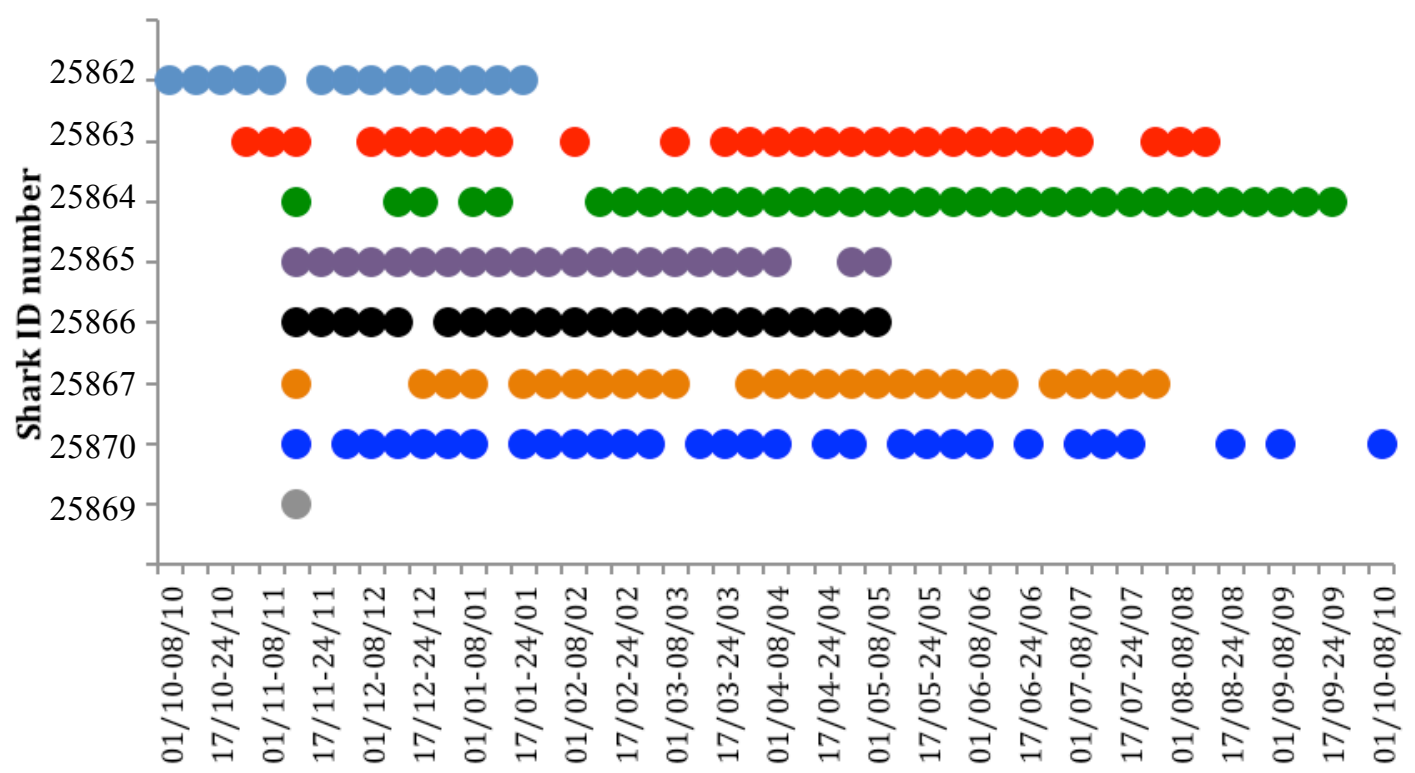

Detection dates (weekly)

Figure 6: Abacus plot showing weekly detection of the eight acoustically tagged pyjama sharks. Shark number 25869 was not detected again after initial tagging (on 11 November, 2015), so it was excluded from the Cormack-Jolly-Seber (CJS) analysis on the acoustic tag data.

\subsection{Goodness of fit testing}

Based on the RELEASE GOF test, there was no over- or underdispersion in the acoustic telemetry weekly sightings data used for the CJS models (i.e. the models adequately fit the data), therefore no adjustments were made to c-hat and the lowest AICc value was used to indicate the best-fit model $\left(\chi^{2}\right.$ $=19.66$, d.f. $=24, \mathrm{p}=0.7158, \mathrm{c}-\mathrm{hat}=1.00)$.

For the conventional tag data used for the robust design, the data were too sparse to get results from the GOF tests (i.e. there were too few recaptures between periods; Appendix A, Table A.2). For that reason, the abundance and survival estimates will need to be taken with high reservations, as GOF could not be properly evaluated. The lowest AICc was used to indicate the best-fit model. 


\subsection{Robust design estimates (conventional tag data): abundance, survival, temporary emigration and capture probability}

Based on the lowest AICc value, the best-fit model (Table 1) included a TL-dependent apparent survival $\left(\varphi_{\mathrm{TL}}\right)$, no temporary emigration $\left(\gamma^{\prime \prime}(0)=\gamma^{\prime}(0)\right)$ and time-constant capture probabilities $(p()=.c($.$) ; i.e. survival is dependent on the length at first capture and remains unchanged over time,$ there is no emigration from the study area and capture probabilities do not change over time). The beta parameters on survival for the best-fit model were estimated to be 0.0135 ( $\beta_{1}$, the slope) and $10.8285\left(\beta_{0}\right.$, the intercept; Table 2). Abundance $(\mathrm{N})$ ranged from a low of 279 sharks to a high of 733 sharks (Fig. 7; Table 3). The rate of apparent annual survival $(\varphi)$ was estimated to be 0.613 year $^{-1}$ for the mean TL $(836.2 \mathrm{~mm})$ of the P. africanum population in Mossel Bay, 0.821 year $^{-1}$ for the upper quartile TL $(915 \mathrm{~mm})$ and 0.393 year $^{-1}$ for the lower quartile TL $(770 \mathrm{~mm}$; Table 3$)$. The odds ratio (OR) of the effect of an increasing TL on survival, using the $\beta_{1}$ parameter $(0.0135)$ and the equation $\exp ^{0.0135^{*} 100}$, showed that for every $100 \mathrm{~mm}$ increase in TL the odds of a shark in this population surviving increases by a factor of 3.7 ; the odds of surviving are more than tripled for a $100 \mathrm{~mm}$ increase in length. The rate of capture and recapture was estimated to be 0.008 year $^{-1}$ (Table 3 ). However, confidence intervals were quite large because of the relatively small sample size and sparse data, potentially inducing imprecision in the estimates. 


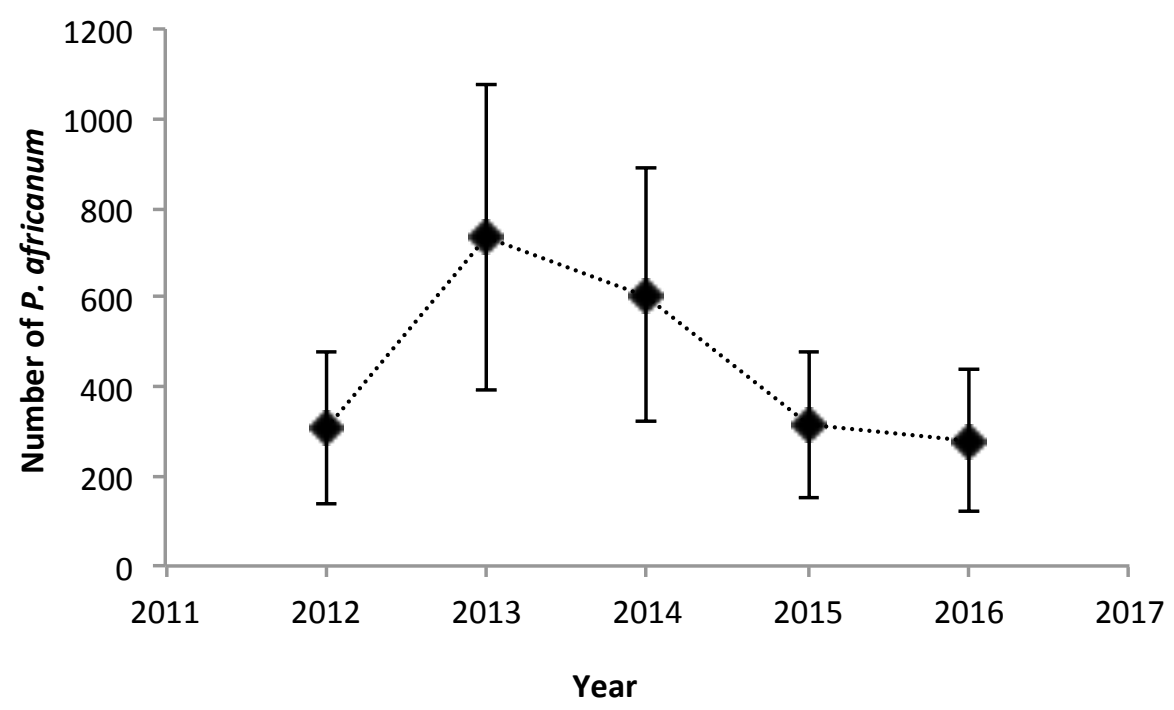

Figure 7: Estimates of yearly abundance $(\mathrm{N}) \pm$ standard error (vertical error bars) calculated from the robust design model.

\subsection{CJS estimates (acoustic tag data): apparent survival and capture probability}

The best-fit model based on the lowest AICc value included time-constant survival ( $\varphi$.) and sexdependent recapture probabilities ( $\mathrm{p}_{\text {sex }}$; i.e. $\varphi$ remains constant (unchanged over time) and $\mathrm{p}$ is dependent on the sex of the shark, but remains unchanged over time; Table 1; Appendix A, Table A.5). The apparent annual survival $(\varphi)$ was estimated to be 0.254 year $^{-1}$. This is a more precise estimate of survival compared to that estimated from the robust design (Table 3) because, although the sample size was small (seven sharks), the resighting (recapture) frequency was high compared to those from the conventional tagging methods, where recaptures were rare. Accordingly, the acoustic resighting data are considerably less sparse than the conventional tagging data, thus increasing the precision in the estimates. The annual rate of capture ( $p$ ) varied between sexes; $p$ was 0.75 week $^{-1}$ for males and 0.85 week $^{-1}$ for females (Table 3), however when scaled up to the full year (the 50 week 
period), the capture probability for both male and female is virtually one (0.9999 and 0.9996 year $^{-1}$, respectively).

Table 1: Best-fit models (model type) showing the assumptions (model), the number of parameters that were estimated (npar), the AICc and the Deviance, used for population (N) and survival estimates. The robust design model uses the conventional tag data, while the CJS model uses the acoustic tag data.

\begin{tabular}{ccccc}
\hline \hline Model type & \multicolumn{1}{c}{ Model } & npar & AICc & Deviance \\
\hline \hline Robust design & $\varphi(\mathrm{TL}) \gamma^{\prime \prime}(0)=\gamma^{\prime}(0) \mathrm{p}()=.\mathrm{c}()$. & 8 & -0.9664 & -18.1277 \\
CJS & $\varphi(.) \mathrm{p}(\mathrm{Sex})$ & 3 & 276.527 & 261.026 \\
\hline \hline
\end{tabular}

Table 2: Beta ( $\beta$ ) parameters on survival (for the robust design model), the $95 \%$ confidence intervals (C.I.) and standard errors (S.E.). $\beta_{1}$ and $\beta_{0}$ were used to produce the robust design survival estimates for the mean total length (TL), upper and lower quartile TLs of Poroderma africanum in Mossel Bay.

\begin{tabular}{llll}
\hline \hline & $\boldsymbol{\beta}$ & 95\% C.I. & S.E. \\
\hline \hline$\beta_{1}$ (slope) & 0.0135 & $-0.0133-0.0403$ & 0.01368 \\
$\beta_{0}$ (intercept) & -10.8285 & $-31.8877-10.2307$ & 10.7444 \\
\hline \hline
\end{tabular}


Table 3: Results of the best fit models showing estimates and $95 \%$ confidence intervals of abundance $(\mathrm{N})$ over five years from the robust design, rate of apparent annual survival $(\varphi)$ for the mean, upper quartile and lower quartile total lengths and annual rate of annual capture (p) from the robust design (conventional tag data) and CJS model (acoustic data). Based on best-fit models shown in Table 1. Note: 'm:' denotes estimate for males and 'f:' denotes estimates for females.

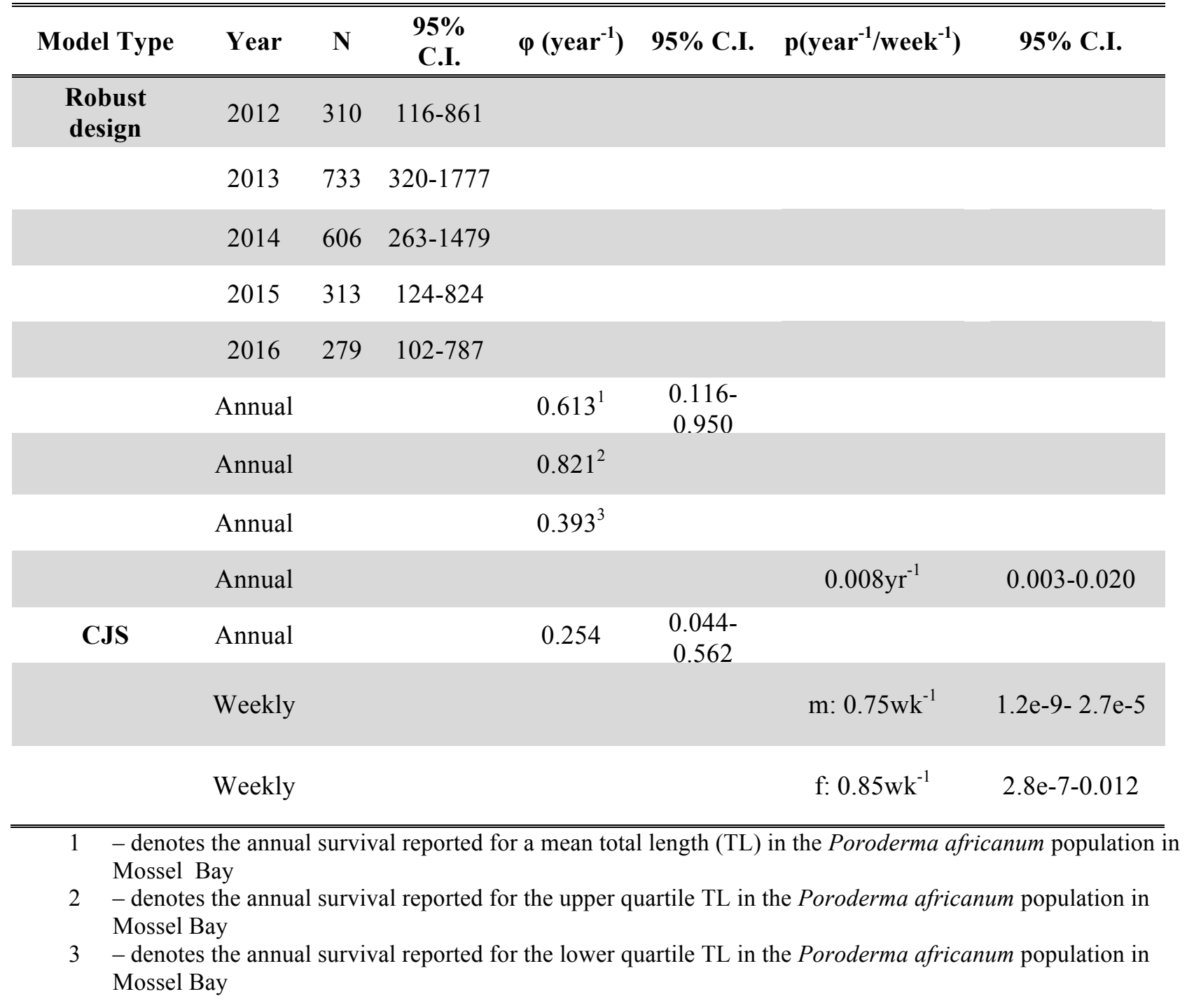

\subsection{Growth curve (conventional tag data)}

Somatic growth rate $(\mathrm{k})$ was relatively slow for pyjama sharks $\left(0.213\right.$ year $\left.^{-1}\right)$, as expected.

Furthermore, k could be slightly biased because there were no juvenile-sized sharks included in this 
study; the smallest shark in this study was $570 \mathrm{~mm}$, which is late adolescent size. Based on the Von Bertalanffy growth curve constructed from equations (2) through (5) (Fig. 8), the largest shark in this sample (1050mm) was estimated to be approximately $12-15$ years old.

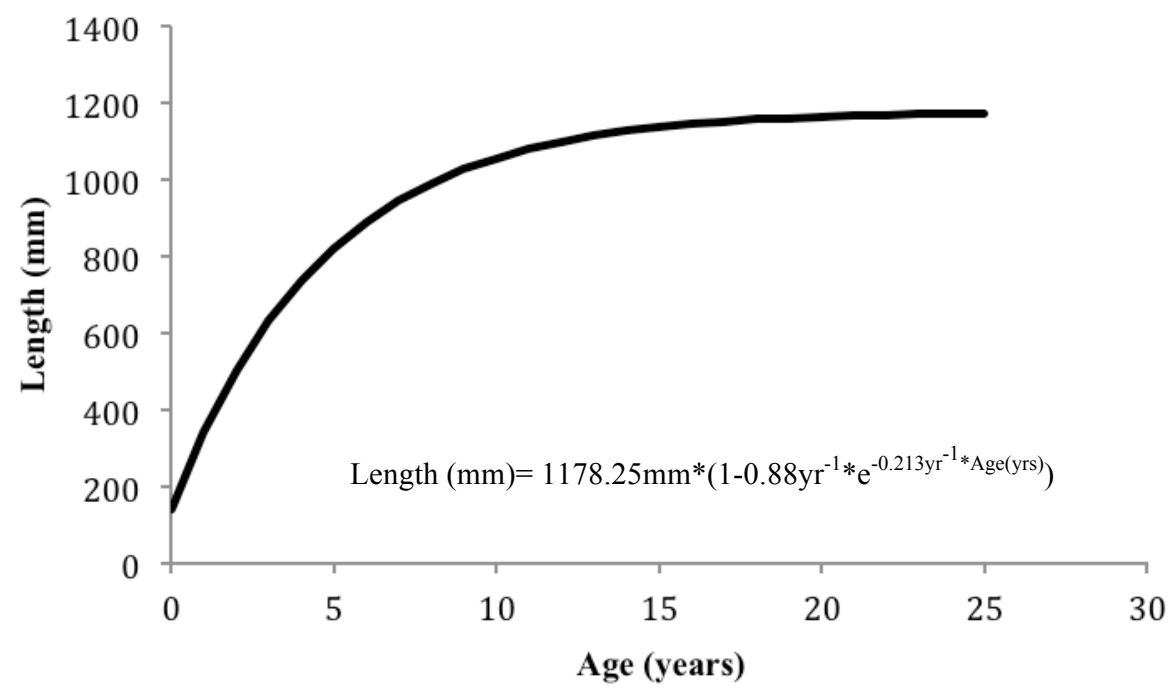

Figure 8: Von Bertalanffy growth curve constructed using equation (4), where $\mathrm{k}$ is 0.213 year $^{-1}$ (an estimated average for Poroderma africanum in Mossel Bay), b is $0.88 \mathrm{year}^{-1}$, and $\mathrm{L}_{\infty}$ is $1178.25 \mathrm{~mm}$. This growth curve was modeled based on the conventional tagging data. 


\section{Discussion}

Although dependable demographic analyses are important to apply effective management measures, especially for endemic species, it is difficult to know how reliable estimated demographic parameters really are in most wildlife populations. Estimates of apparent survival and abundance are seemingly influenced by the timing of tagging and the age- and sex-class of the sample, hence it is important to include individuals from both sexes and all age-classes to increase precision of the analysis (Lee et al. 2014). Based on the length-frequency distribution, it has been determined that no juvenile sharks were tagged for this study. The main reason for this being that juvenile sharks were too small to be fit with the tags. Therefore, the models presented in this study are only applicable to adults and thus the estimates are not representative of all age classes in the population.

Excluding certain months for the robust design analysis was done to avoid violating the assumption that there needs to be adequate time between primary occasions to allow the study population to change (Kendall 1999; Silva et al. 2009). Violation of this assumption would arise if one primary period ended in December and the next one began in January, as there would be no adequate time period for the population to potentially change between the two primary periods. Since months January through March had considerably lower sampling effort compared to the rest of the year, these months were reasonably chosen to exclude from the study.

The robust design was chosen for this study to assess abundance rather than a purely open population or closed population model because, while P. africanum is generally a weak swimmer and not known to migrate long distances (Springer 1979), there has been evidence of a couple of individuals that have traveled as far as $300 \mathrm{~km}$ (Escobar-Porras 2009). Furthermore, this is a longterm study and those periods of "openness" are necessary as the structure of the population could 
change over time (Heupel and Bennett 2007). Because of the sparseness of the data and the large confidence intervals in survival estimates from the long-term conventional tag data, a CJS analysis using the acoustic telemetry data was thereby carried out, as the data were considerably less sparse. The idea behind this is that using a dataset with more frequent capture (resight) data could increase precision in the estimates of apparent survival for pyjama sharks in Mossel Bay. Sightings from the acoustic telemetry method were considerably more frequent than from the conventional tag method, thus it is assumed that the apparent survival estimates obtained using the telemetry data are more precise than those using the conventional tag data. Since the acoustic telemetry data was only available for one year, it was not used in the robust design to estimate abundance, as abundance is usually estimated over the long-term (Pollock et al. 1990; Cooch and White 2006).

As an endemic species, $P$. africanum is more susceptible to reductions in range, abundance and genetic variability compared to species that are widely distributed (Isik 2011). Thus highlighting the significance of understanding the abundance and demographic characteristics of this species even in a small bay such as Mossel Bay. Not much is known about P. africanum in South Africa. While there have been few studies done on this species in the Eastern and Western Capes (Dainty 2002; Escobar-Porras 2009), this is the first known study on this species in Mossel Bay. The following sections explore our findings on the $P$. africanum population in Mossel Bay in greater detail in comparison to the populations in the Eastern and Western Capes (Dainty 2002; Escobar-Porras 2009). 


\subsection{Abundance estimates}

Although the robust design models are designed to deal with imperfect detection and include behavioral influences (e.g. trap-shyness/happiness), other factors such as the sampling methods used, the number of recaptures and low capture probabilities can result in overestimates of abundance (Cerchio 1998; Lettink and Armstrong 2003). For example, there were very few recaptures in this study from the conventional tag data $(\mathrm{p}=0.008$ from the robust design). Looking at the data, it is apparent that many individuals that were captured during the first periods were not seen again in the later periods, and many individuals that were not seen in the earlier periods were only seen (for the first time) in the later periods (Appendix A, Table A.2). Hence the low number of recaptures and infrequent capture histories available in this study, and thus sparse data from the conventional tagging method. For example, if an individual was captured once during the first periods of the study and not seen again, it would have a capture history that looks something like ' $110000000000000 \ldots$..' and so on, Where an individual not initially seen until the later periods would have one looking like '0000000000000100100...'. This sparseness in the recaptures then could result in an overestimate of abundance (Cerchio 1998; Lettink and Armstrong 2003), which is likely what is seen in this study.

As an endemic species, it is surprising that the population estimates (279 to 733 sharks) were relatively high (Isik 2011). However, it is not surprising that the number of recaptures were very low, making the data very sparse and the abundance estimates inflated. Furthermore, although results suggest that pyjama sharks are relatively abundant in Mossel Bay, these estimates need to be taken with caution because the recaptures were rare, making the conventional tag data too sparse to properly assess GOF of the data. 
Escobar-Porras (2009) tagged 14 pyjama sharks at Rebelsrus in the Eastern Cape and estimated the population size to be 47 sharks in that area. However, similarly to this study, confidence was low (95\% C.I. 19-268) due to the small sample size and sparse recaptures. To increase confidence in the estimates, a larger sample size that is inclusive of all age-classes is necessary; neither this study nor Escobar-Porras's (2009) study included juvenile sharks, thus the estimates cannot be applied to juveniles and therefore do not represent all age classes in the population. In the Western Cape, while actual abundance was not estimated, Dainty (2002) noted that Poroderma spp. are some of the most abundant predatory reef fish within False Bay, and observed that all age classes and sexes are present in the same areas. Thus, indicating that intraspecific competition for resources is likely occurring within the False Bay population, making this species a valuable ecosystem regulator. This suggests that intraspecific competition is also probable in the Mossel Bay population. However, further studies must be conducted that are inclusive of all age classes of $P$. africanum in Mossel Bay.

The wide confidence intervals in our abundance estimates from year to year suggest that a larger sample size and less-sparse data are necessary to more precisely assess abundance. Overall, although these estimates need to be taken with caution, it seems that this is a good baseline observation of abundance for this population and that the population trend of pyjama sharks in Mossel Bay is relatively stable. 


\subsection{Apparent survival estimates and capture probabilities}

Apparent annual survival rate estimates from the robust design, using the conventional tag data, were higher than those estimates from the CJS analysis on the acoustic telemetry data $(0.393-0.821$ vs 0.254 year $\left.^{-1}\right)$. The acoustic data are considerably less sparse than the conventional recapture data, hence resulting in more precise estimates of survival for pyjama sharks in Mossel Bay. Although the conventional tag data are sparse, and no juvenile sharks were tagged in this study (only sub-adults and adults), the TL covariate on survival in the robust design could act as an acceptable proxy for the size of the sharks, thus may aid in explaining the variation in survival. However, there is still some limitation to this as many of the sub-adult sharks that were tagged (Fig. 4), are still growing from year to year, thus their survival is expected to change (Cooch and White 2006).

For both model types, the candidate model estimated apparent survival as time-constant, meaning that the probability of surviving into the next session remained the same throughout each session. However, the robust design suggested that this fixed survival rate is also dependent on the length of first capture of the individual. The odds ratio (OR) of 3.7 suggests that survival of $P$. africanum in Mossel Bay increases as sharks grow larger (more than a three-fold increase for every $100 \mathrm{~mm}$ increase in length). Gallahger et al. (2014) evaluated the survival of multiple shark species caught as bycatch in pelagic longline fisheries. Their results indicated that survival of silky, blue, dusky and night sharks increased significantly with increasing length. Additionally, studies conducted by Bradshaw et al. (2007) and Holmberg at al. (2009) on whale shark (Rhincodon typus) survival in Ningaloo Marine Park in Western Australia concluded that annual mean survival increased as mean total length (TL) increased, suggesting that increases in length could be a strategy for improving 
survival in many shark species. It potentially also allows increased fecundity in many shark species (Bradshaw et al. 2007; Holmberg et al. 2009).

Juvenile survival is presumably different from adult survival; $P$. africanum is an oviparous species, a trait common in family Scyliorhinidae. Once the mother attaches the egg case to the substrate, there is no further parental care (Concha et al. 2010). The hatched pups are generally small (size at hatching is $140 \mathrm{~mm}$ for pyjama sharks) because they only receive, and are limited to, the nutrients available inside the egg case (Highly Migratory Species Management Division 2003). Commonly, juveniles are weak, inexperienced and vulnerable compared to adults, thus they have their own set of challenges to overcome in order to successfully survive and reach adulthood (Krzyszczyk 2013). The potential difference between juvenile and adult survival suggests that the survival rate estimated in this study might not be representative of all age classes in population (i.e. it can only be applied to sub-adults and adults). Poroderma africanum also exhibits low fecundity, a characteristic of most elasmobranch species (Stevens et al. 2000), hence juvenile survival is critical for maintaining and growing the population (Pardo et al. 2016). Although juvenile survival may differ from adult survival, juvenile elasmobranch survival is assumed to be relatively high compared to juvenile teleost survival; this is a result of the low fecundity trait in elasmobranchs. However, the difference in juvenile survival compared to adult survival is still dependent on the species-specific life history characteristics and population demographics (Pardo et al. 2016).

The relatively low apparent survival rates suggest that pyjama sharks are readily influenced by changes in their environment (Lee et al. 2014). The results in this study should be further expanded upon to assess to what extent certain influences, such as climate change and fishing pressures, have on this species. While our survival estimates act as a notable baseline estimate for this population, it 
is necessary for further studies to include data for all age classes to account for the life history characteristics known for the different life stages of $P$. africanum.

\subsection{Emigration and residency}

As expected, the best-fit robust design model was one with no temporary emigration. Benthic catsharks are weak swimmers (Springer 1979), indicating that they do not generally migrate long distances. This suggests that the pyjama shark population in Mossel Bay is separate to the pyjama shark populations in the Eastern and Western Capes of South Africa (i.e. there are separate subpopulations within their distribution range). Escobar-Porras (2009) concluded that pyjama sharks in Rebelsrus (Eastern Cape) exhibited strong residency with no evidence of migrations, further indicating that there are multiple sub-populations of pyjama sharks within their range. Dainty (2002) also noted that pyjama sharks in False Bay (Western Cape) exhibited strong residency, with some sharks recaptured in the same location they were tagged after five years.

Sub-populations have been observed in a closely related Scyliorhinid species, the small spotted catshark, Scyliorhinus canicula, a species that also does not migrate long distances (Gubili et al. 2014). S. canicula ranges from Norway to Senegal (Atlantic Ocean) and in the Mediterranean Sea. Distinct populations of this species have been observed in the Northeast Atlantic and in the Mediterranean (Rinelli et al. 2005; Gubili et al. 2014). The genetic variation between these subpopulations could be a result of local adaptation to the environment. Sexual maturity was reached earlier in the Mediterranean population than in the Northeast Atlantic population (Rinelli et al. 2005; Gubili et al. 2014). Furthermore, population expansion was observed in the Atlantic, while population stability was noted in the Mediterranean. The stability noted in the Mediterranean could have arisen 
because of the deep basins acting as a suitable habitat during sea- level and -temperature fluctuations (Gubili et al. 2014). This suggests that the population expansion observed in the Atlantic could be a result of the sharks being unable to adapt to the environmental changes. Identifying sub-populations of non-migratory species, such as $S$. canicula and $P$. africanum has essential conservation implications, where conservation measures need to be implemented based on the demographic characteristics of each sub-population individually (Gubili et al. 2014).

Results suggest that, as an endemic species with a relatively small population and high degree of residency, pyjama sharks are vulnerable to local anthropogenic activities (Escobar-Porras 2009). Thus, management strategies such as MPAs (Marine Protected Areas) or fishing gear restrictions could be necessary as preventative measures for the conservation and maintenance of this species. While pyjama sharks are not a commercially targeted species, this population is resident in the area and the population as a whole is endemic to South Africa (Fig. 1). This suggests that they are susceptible to changes in the environment such as habitat destruction, climate change or removal of prey (Skarbek 2008).

\subsection{Growth rate}

The von Bertalanffy growth parameters derived in this study could be under-estimated as there were no juvenile sharks in the sample. The somatic growth rate $(\mathrm{k})$ in this study was calculated by incorporating the length at first capture and the length at recapture (equation (2)). As sharks get older and reach maturity, they grow slower; they continue to grow throughout their lifetime but growth slows as they age (Helfman and Burgess 2014). This suggests that using the length at first capture and at recapture for sharks that have already reached maturity (i.e. they are growing slower than younger 
sharks) could result in an elevated growth rate estimate. Thus in this study, data for sharks that were of late adolescent size at the time of first capture were used to calculate the growth rate rather than data for a shark that was of adult (or near adult) size (e.g. $824 \mathrm{~mm}$ and greater).

Dainty (2002) estimated von Bertalanffy growth parameters for pyjama sharks from analysis of vertebrae using a sample consisting of all age-classes. This resulted in a growth rate (k) of 0.036 year $^{-1}$ compared to 0.213 year $^{-1}$ calculated in this study. Based on Dainty's (2002) estimate, the largest shark in this study (1050mm TL) would be approximately 30 years old, compared to 15 years old suggested by the growth curve constructed in this study.

The growth rate obtained by Dainty (2002) could be more realistic than the growth rate calculated in this study as Dainty (2002) analyzed vertebrae of sharks from all age classes to determine their age, thus considering individual variability in growth (Hart and Chute 2009). It is valuable to assess growth and survival over all age classes, as it will aid in our understanding of the different life stages and characteristics of this population (Bowerman and Budy 2012). Since growth rate does decrease as sharks age, further studies conducted should incorporate size data for juvenile individuals into the data presented in this study to produce a more precise growth analysis for this population. Additionally, the growth rate for this population could be a strategy to adapt to changing temperatures, increase juvenile survival or reduce juvenile predation (Meyer et al. 2012). This information is thus necessary to fill in the knowledge gap of $P$. africanum in Mossel Bay.

Fabens' (1965) modified von Bertalanffy growth (VBG) equation was chosen in this study because it allowed estimation of growth parameters from recapture data where the age at first capture is unknown. The VBG curve is common in stock assessments as it is constructed using biologically relevant parameters such as maximum length in the population and the growth rate relative to that maximum length (Schofield et al. 2013). For recapture data, there are two parameterizations of the 
VBG curve that are commonly used. These are length at first capture, which is applied in Fabens' (1965) method, and age at first capture, length-at-age models (Schofield et al. 2013). The length-atage models are usually not used with recapture data unless additional data are available because the age at capture and age at length zero cannot be established based on capture observations alone (Hart and Chute 2009; Schofield et al. 2013). Nonetheless, Fabens' (1965) method could result in biased growth parameter estimates because it does not consider individual variability (i.e. that growth varies among individuals; Hart and Chute 2009). This is because it uses calculations to determine age, rather than ageing fish individually (e.g. through vertebrae analysis). However, additional data on growth and age were not available for this study, thus Fabens' method was chosen to estimate growth.

\subsection{Conclusions}

Overall, this study has demonstrated that mark-recapture methods can provide abundance and demographic characteristics "robust" to variation in detection, movement and other behavioral characteristics, even when the sample size is relatively small and the data are sparse. This is the first known study on the abundance and population structure of $P$. africanum done in Mossel Bay and therefore provides the first baseline estimates of abundance for this species in this area, notwithstanding the potential imprecisions in the estimates. The abundance estimates obtained from this study suggest that the population is stable. However, these estimates need to be taken with considerable caution, as recaptures were very low, thus data were sparse and goodness of fit could not be accurately assessed. 
To more appropriately estimate the abundance and demographic characteristics of $P$.

africanum, future investigations must include samples from all age- and sex-classes and a large sample size relative to the species of interest.

\section{References}

Abadi, F., Gimenez, O., Arlettaz, R. and M. Schaub. (2010). An assessment of integrated population models: bias, accuracy, and violation of the assumption of independence. Ecology, 9(1), 7-14.

Anderson, T., Elser, J.J. and D.O. Hessen. (2004). Stoichiometry and population dynamics. Ecology Letters, 7, 884-900. doi: 10.1111/j.1461-0248.2004.00646.x.

Bass, A.J., D'Aubrey, J.D. and N. Kistnasamy. (1975). Sharks of the east coast of southern Africa II: the families Scyliorhinidae and Pseudotriakidae. Investigational Report of the Oceanographic Research Institute, 37, 1-64.

Bendiab, A.A.T., Mouffok, S. and Z. Boutiba. (2012). Reproductive biology and growth of Lesser Spotted Dogfish Scyliorhinus canicula (Linnaeus, 1758) in Western Algerian coasts (Chondrichthyes, Scyliorhinidae). Biodiversity Journal, 3(1), 41-48.

Best, L.N., Attwood, C.G., da Silva, C. and S.J. Lamberth. (2013). Chondrichthyan occurrence and abundance trends in False Bay, South Africa, spanning a century of catch and survey records. African Zoology, 48(2), 201-227.

Bjorndal, K.A., Bolten, A.B., Coan Jr, A.L. and P. Kleiber. (1995). Estimation of green turtle (Chelonia mydas) growth rates from length-frequency analysis. Copeia, 1, 71-77.

Bond, M.E., Babcock, E.A., Pikitch, E.K., Abercrombie, D.L., Lamb, N.F. and D. Chapman. (2012). Reef sharks exhibit site-fidelity and higher relative abundance in marine reserves on the Mesoamerican barrier reef. Plos One, 7(3). doi: 10.1371/journal.pone.0032983.

Bozdogan, H. (1987). Model selection and Akaike's Information Criteria (AIC): the general theory and its analytical extensions. Psychometrika, 52(3), 345-370.

Bradshaw, C.J.A., Mollet, H.F. and M.G. Meekan. (2007). Inferring population trends for the world's largest fish from mark-recapture estimates of survival. Journal of Animal Ecology, 76, 480489.

Burnham, K.P. and D.R. Anderson. (2002). Multimodal inference: understanding AIC and BIC in model selection. Sociological Methods and Research, 33(2), 261-304.

Chao, A. and R.M. Huggins. (2005). Modern closed-population capture-recapture models. In Amstrup, S.C., McDonald, T.L. and B.F.J. Manly (Eds.), Handbook of Capture-Recapture Analysis (pp. 58-88). Princeton University Press, Princeton.

Cerchio, S. (1998). Estimates of humpback whale abundance off Kauai, 1989 to 1993: evaluating biases associated with sampling the Hawaiian Islands breeding assemblage. Marine Ecology Progress Series, 175, 23-34.

Coelho, R.P.A. (2007). Biology, population dynamics, management and conservation of deep water lantern sharks, Etmopterus spinax and Etmopterus pusillus (Chondrichthyes: Etmopteridae) in southern Portugal (northeast Atlantic). (Doctor of Philosophy in Fisheries Sciences and Technologies, specialty in Fisheries Biology), Universidade do Algarve, Portugal. 
Compagno, L.J.V. (1999). Systematics and body form. In Hamlett, W.C. (Ed.), Sharks, Skates and Rays: the biology of elasmobranch fishes (pp.1-43). The Johns Hopkins University Press, Baltimore.

Compagno, L.J.V. (2001). Sharks of the world. An annotated and illustrated catalogue of shark species known to date. Vol. 2. Bullhead, mackerel and carpet sharks (Heterodontiformes, Lamniformes and Orectolobiformes). FAO Species Catalogue for Fishery Purposes No. 1. Rome. 269pp.

Compagno, L.J.V. 2005. Poroderma africanum. The IUCN Red List of Threatened Species 2005: e.T39348A10211867. http://dx.doi.org/10.2305/IUCN.UK.2005.RLTS.T39348A10211867.en. Downloaded on 13 July 2016.

Concha, F., Bustamante, C., Oddone, M.C., Hernandez, S. and J. Lamilla. (2010). Egg capsules of the dusky catshark Bythaelurus canescens (Carcharhiniformes, Scyliorhinidae) from the southeastern Pacific Ocean. Journal of Fish Biology, 77, 963-971. doi: 10.1111/j.10958649.2010.02736.x.

Cooch, E.G. and G.C. White. (2006). Program MARK: A Gentle Introduction Retrieved from http://www.phidot.org/software/mark/docs/book/.

Dainty, Alison M. (2002). Biology and ecology of four catshark species in the southwestern Cape, South Africa. (Master of Science), University of Cape Town, South Africa.

Dudgeon, C.L., Pollock, K.H., Braccini, J.M., Semmens, J.M. and A. Barnett. (2015). Integrating acoustic telemetry into mark-recapture models to improve the precision of apparent survival and abundance estimates. Oecologia, 178, 761-772. doi: 10.1007/s00442-015-3280-z.

Ebert, D.A., Compagno, L.J.V. and P.D. Cowley. (2006). Reproductive biology of catsharks (Chondrichthyes: Scyliohinidae) off the west coast of southern Africa. ICES Journal of Marine Sciences, 62, 1053-1065. doi: 10.1016/j.icesjms.2006.04.016.

Escobar-Porras, J. (2009). Movement patterns and population dynamics of four catsharks endemic to South Africa. (Master of Science), Rhodes University, South Africa.

Escobar-Porras, J. and B.Q. Mann. (2013). Southern African Marine Linefish Species Profiles. South African Association for Marine Biological Research and Oceanographic Research Institute, Durban.

Fabens AJ (1965) Properties and fitting of the von Bertalanffy growth curve. Growth, 29, 265-289. Froese, R., \& Binohlan, C. (2000). Empirical relationships to estimate asymptotic length, length at first maturity and length at maximum yield per recruit in fishes, with a simple method to evaluate length frequency data. Journal of Fish Biology, 56, 758-773.

Gallagher, A.J., Orbesen, E.S., Hammerschlag, N. and Serafy, J.E. (2014). Vulnerability of oceanic sharks as pelagic longline bycatch. Global Ecology and Conservation, 1, 50-59.

Gordon, A.L. (1988). The South Atlantic: an overview of results from 1983-88 research. Oceanography, 12-58.

Gubili, C., Sims,D.W., Veríssimo, A., Domenici, P., Ellis, J., Grigoriou, P., Johnson, A.F., McHugh, M., Neat, F., Satta, A., Scarcella, G., Serra-Pereira, B., Soldo, A., Genner, M.J., and A.M. Griffiths. (2014). A tale of two seas: contrasting patterns of population structure in the smallspotted catshark across Europe. Royal Society Open Science, 1, 1-18.

Harry, A.V., Tobin, A.J., Simpfendorfer, C.A., Welch, D.J., Mapleston, A., White, J., Williams, A.J. and J. Stapley. (2011). Evaluating catch and mitigating risk in a multispecies, tropical, inshore shark fishery within the Great Barrier Reef world heritage area. Marine and Freshwater Research, 62, 710-721. 
Hart, D.R. and A.S. Chute. (2009). Estimating von Bertalanffy growth parameters from growth increment data using linear mixed-effects model, with an application to the sea scallop Placopecten magellanicus. ICES Journal of Marine Sciences, 66, 2165-2175.

Heemstra, P. and E. Heemstra. (2004). Coastal Fishes of South Africa. National Inquiry Service Centre (NISC) of South Africa and South African Institute for Aquatic Biodiversity (SAIAB).

Helfman, G. and G.H. Burgess. (2014). Sharks: The Animal Answer Guide. Johns Hopkins University Press, Baltimore.

Heupel, M.R. and M.B. Bennett. (2007). Estimating abundance of reef-dwelling sharks: A case study of the epaulette shark, Hemiscyllium ocellatum (Elasmobranchii: Hemiscyllidae). Pacific Science, 61, 383-394.

Heupel, M.R., Semmens, J.M. and A.J. Hobday. (2006). Automated acoustic tracking of aquatic animals: scales, design and deployment of listening station arrays. Marine and Freshwater Research, 57, 1-13.

Highly Migratory Species Management Division, NOAA. (2003). Final Amendment 1 to the Fishery Management Plan for Atlantic Tunas, Swordfish, and Sharks. United States National Marine Fisheries Service, Silver Spring.

Holmberg, J., Norman, B. and Z. Arzoumanian. (2009). Estimating population size, structure, and residency time for whale sharks Rhincodon typus through collaborative photo-identification. Endangered Species Research, 7, 39-53.

Human, B.A. (2006). Size-corrected shape variation analysis and quantitative species discrimination in a morphologically conservative catshark genus, Poroderma Smith, 1837 (Chondrichthyes: Carcharhiniformes: Scyliorhinidae). African Natural History, 2, 1-15.

Isik, K. (2011). Rare and endemic species: why are they prone to extinction? Turkish Journal of Botany, 35, 411-417. doi: 10.3906/bot-1012-90.

Jewell, O.J.D., Johnson, R.L., Gennari, E. and M.N. Bester. (2013). Fine scale movements and activity areas of white sharks (Carcharodon carcharias) in Mossel Bay, South Africa. Environmental Biology of Fishes, 96(7). doi: 10.1007/s10641-012-0084-4.

Kendall, W.L. (1999). Robustness of closed capture-recapture methods to violations of the closure assumption. Ecology, 80(8), 2517-2525.

Krzyszczyk, E. B. (2013). Age determination, life history and juvenile behavior in bottlenose dolphins (Tursiops SP.) in Shark Bay, Australia. (Doctor of Philosophy in Biology), Georgetown University, USA.

Lebreton, J.D., Burnham, K.P., Clobert, J. and D.R. Anderson. (1992). Modeling survival and testing biological hypotheses using marked animals: a unified approach with case studies. Ecological Monographs, 62(1), 67-118.

Lee K.A., Huveneers, C., Gimenez, O., Peddemors, V. and R.G. Harcourt. (2014). To catch or resight? A comparison of demographic parameter estimates obtained from mark-recapture and mark-resight models. Biodiversity Conservation, 23, 2781-2800. doi: 10.1007/s10531-0140748-9.

Lettink, M. (2012). Herpetofauna: population estimates (using capture-mark-recapture data). Department of Conservation, New Zealand.

Lettink, M. and D.P. Armstrong. (2003). An introduction to using mark-recapture analysis for monitoring threatened species. Department of Conservation Technical Series, 28(A), 5-32.

Mathews, C.P. and M. Samuel. (1990). The relationship between maximum asymptotic length in fishes. Fishbyte ICLARM, 14-16. 
McFarlane, G.A., Wydoski, R.S. and E.D. Prince. (1990). External tags and marks: historical overview of the development of external tags and marks. American Fisheries Society Symposium, 7, 9-29.

Massutí, E. and J. Moranta. (2003). Demersal assemblages and depth distribution of elasmobranchs from the continental shelf and slope off the Balearic Islands (western Mediterranean). ICES Journal of Marine Sciences, 60, 753-766.

Moyle, P.B. and J.J. Cech, Jr. (2004). Fishes: An Introduction to Ichthyology (5th ed.). Pearson Benjamin Cummings, San Francisco.

Musick, J.A. and R. Bonfil. (2005). Management techniques for elasmobranch fisheries. FAO, Rome.

Nash, R.D.M., Valencia, A.H. and A.J. Geffen. (2006). The origin of Fulton's condition factorsetting the record straight. Fisheries, 31(5), 236-238.

Olsen, A.M. (1984). Synopsis of biological data on the school shark, Galeorhinus australis (Macleay 1881). FAO Fisheries Synopsis, 139, 1-42.

Otis, D.L., Burnham, K.P., White, G.C. and D.R. Anderson. (1978). Wildlife Monographs: Statistical Inference from Capture Data on Closed Animal Populations (Vol. 62). Utah State University: The Wildlife Society.

Pardo, S.A., Kindsvater, H.K., Reynolds, J.D. and N.K. Dulvy. (2016). Maximum intrinsic rate of population increase in sharks and chimaeras: the importance of survival to maturity. Canadian Journal of Fisheries and Aquatic Sciences, 73, 1-5.

Pauly, D. (1984). Fish population dynamics in tropical waters: A manual for use with programmable calculations. ICLARM Studies and Reviews, 8, 1-325.

Payne, J., Moustahfid, H., Mayorga, E., Branton, R., Mihoff, M. and L. Bajona. (2013). A metadata convention for animal acoustic telemetry data: IOOS animal acoustic telemetry observations (AAT). Retrieved July 2016 from https://storage.googleapis.com/google-code-archivedownloads/v2/code.google.com/ioostech/AAT\%20Metadata\%20Convention\%20v1.2.pdf

Pine, W.E., Pollock, K.H., Hightower, J.E., Kwak, J.E. and J.A. Rice. (2003). A review of tagging methods for estimating fish population size and components of mortality. Fisheries, 28(10), 10-23.

Pollock, K.H. (1981). Capture-recapture models: a review of current methods, assumptions, and experimental design. In Ralph, C.J. and J.M. Scott (Eds), Estimating numbers of terrestrial birds. Studies in Avian Biology, 6, 426-435.

Pollock, K.H. (1982). A capture-recapture design robust to unequal probability of capture. Journal of Wildlife Management, 46(3), 752-757.

Pollock, K.H., Nichols, J.D., Brownie, C. and J.E. Hines. (1990). Statistical inference for capturerecapture experiments. Wildlife Monographs, 107, 3-97.

Posada, D. and T.R. Buckley. (2004). Model selection and model averaging in phylogenetics: advantages of Akaike Information Criterion and Bayesian approaches over likelihood ration tests. Systematic Biology, 53(5), 793-808. doi: 10.1080/10635150490522304.

Richter, H., Luckstadt, C., Focken, U.L. and K. Becker. (2000). An improved procedure to assess fish condition on the basis of length-weight relationships. Archive of Fishery and Marine Research, 48(3), 226-235.

Rinelli, P., Bottari, T., Florio, G., Romeo, T., Giordano, D., and S. Greco. (2005). Observations on distribution and biology of Galeus melastomus (Chondrichthyes, Scyliorhinidae) in the southern Tyrrhenian Sea (central Mediterranean). Cybuim, 29(1), 41-46. 
Ryklief, R., Pistorius, P.A. and R. Johnson. (2014). Spatial and seasonal patterns in sighting rate and life-history composition of the white shark Carcharodon carcharias at Mossel Bay, South Africa. African Journal of Marine Science, 36(4), 449-453. doi: 10.2989/1814232X.2014.967296.

Schaub, M. and F. Abadi. (2011). Integrated population models: a novel analysis framework for deeper insights into population dynamics. Journal of Ornithology, 152, S227-S237. doi: 10.1007/s 10336-010-0632-7.

Schofield, M.R., Barker, R.J. and P. Taylor. (2013). Modeling individual specific fish length from capture-recapture data using the von Bertalanffy growth curve. Biometrics, 69, 1012-1021. doi: 10.1111/biom.12069.

Silva, M.A., Magalhaes, S., Prieto, R.,Serrao Santos, R. and P.S. Hammond. (2009). Estimating survival and abundance in a bottlenose dolphin population taking into account transience and temporary emigration. Marine Ecology Progress Series, 392, 263-276. doi: $10.3354 /$ meps08233.

Skarbek, Carl. (2008). A review of endemic species in the eastern Arc Afromontane region: importance, inferences and conservation. Macalester Reviews in Biogeography, 1(Article 3).

Smith, H.C., Pollock, K., Waples, K., Bradley, S. and L. Bejder. (2013). Use of the robust design to estimate seasonal abundance and demographic parameters of a coastal bottlenose dolphin (Tursiops aduncus) population. Plos One, 8(10). doi: 10.1371/journal.pone.0076574.

Speed, C.W., Field, I.C., Meekan, M.G. and C.J.A. Bradshaw. (2010). Complexities of coastal shark movements and their implications for management. Marine Ecology Progress Series, 408, 275-293. doi: 10.3354/meps08581.

Springer, S. (1979). A revision of the catsharks, family Scyliorhinidae. NOAA Technical Report NMFS Circular, 422, 160pp.

Stevens, J.D., Bonfil, R., Dulvy, N.K. and P.A. Walker. (2000). The effects of fishing on sharks, rays and chimeras (chondrichthyans), and the implications for marine ecosystems. ICES Journal of Marine Sciences, 57, 476-494. doi: 10.1006/jmsc.2000.0724.

Switzer, P.V. (1993). Site fidelity in predictable and unpredictable habitats. Evolutionary Ecology, 7, 533-555.

Tolley, K.A., Raw, R.N.V., Altwegg, R. and G.J. Measey. (2010). Chameleons on the move: survival and movement of the Cape dwarf chameleon, Bradypodion pumilum, within a fragmented urban habitat. African Zoology, 45(1), 99-106.

van der Elst, R.P. and F. Adkin. (Eds) (1991). Marine linefish. Priority species and research objectives in southern Africa. Oceanographic Research Institute, Durban.

Vemco. (2014). V16 coded transmitters datasheet (pp. 1-3). Vemco, Nova Scotia, Canada: AMIRIX Systems Inc. Retrieved July 2016 from https:/vemco.com/wp-content/uploads/2014/05/v16coded.pdf.

Webber, D. (2009). VEMCO acoustic telemetry new user guide. AMIRIX Systems Inc. Nova Scotia, Canada: VEMCO. Retrieved July 2016 from https://vemco.com/wpcontent/uploads/2012/11/acoustic_telemetry.pdf.

White, S.A., McHugh, P.A., Glover, C.N. and A.R. McIntosh. (2015). Trap-shyness subsidence is a threshold function of mark-recapture interval in brown mudfish Neochanna apoda populations. Journal of Fish Biology, 87, 967-980. doi: 10.1111/jfb.12770.

Williams, B.K., Nichols, J.D. and M.J. Conroy. (2002a). Introduction to population ecology. In Williams, B.K., Nichols, J.D. and M.J. Conroy (Eds). Analysis and management of animal 
populations: modeling, estimation, and decision making (pp. 3-9). Academic Press, San Diego.

Williams, B.K., Nichols, J.D. and M.J. Conroy. (2002b). Combining closed and open mark-recapture models: the robust design. In Williams, B.K., Nichols, J.D. and M.J. Conroy (Eds). Analysis and management of animal populations: modeling, estimation, and decision making (pp.524553). Academic Press, San Diego.

Wisniewski, J.M., Abbott, S. and A.M. Gascho Landis. (2015). An evaluation of streamflow augmentation as a short-term freshwater mussel conservation strategy. River Research and Applications. doi: 10.1002/rra.2937. 


\section{Appendix A}

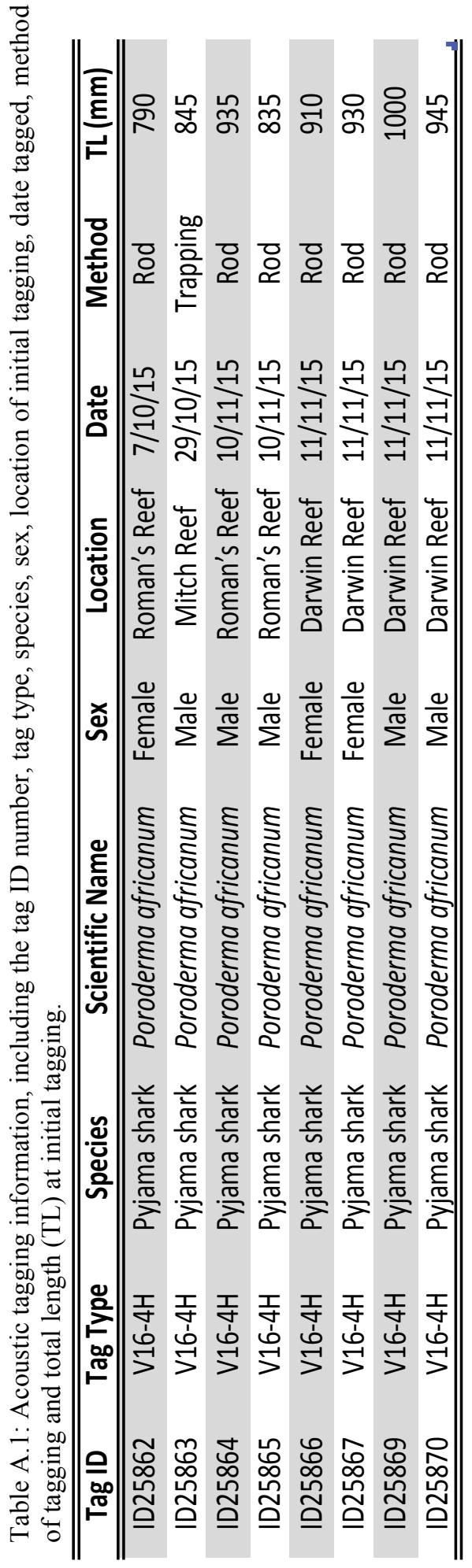


Table A.2: Conventional tagging capture history data, including the tag ID number, the monthly capture history (ch), the frequency of ch and the total length ( $\mathrm{mm}$ ) at first capture. This was used in the robust design model. A ' 1 ' denotes a capture/recapture and a ' 0 ' denotes that an animal was not caught during that period. The ch are the secondary periods, where the first four represent the secondary periods within the first primary period, the next nine represent those within the second primary period, and so on (there are 32 in total. See Fig. 3 above). Ch were very low for this study.

\section{Tag ID Capture History (conventional tag data) Frequency Total Length ( $\mathrm{mm})$}

\begin{tabular}{|c|c|c|c|}
\hline D143724 & 10000000000000000000000000000000 & 1 & 640 \\
\hline D143789 & 10000100000000000000000000000000 & 1 & 770 \\
\hline D143791 & 10000000000000000000000000000000 & 1 & 670 \\
\hline D143795 & 01000000000000000000000000000000 & 1 & 920 \\
\hline D143641 & 00100000000000000000000000000000 & 1 & 950 \\
\hline D143642 & 00100000000000000000000000000001 & 1 & 950 \\
\hline D143643 & 00100000000000000000000000000000 & 1 & 898 \\
\hline D143644 & 00100000000000000000000000000000 & 1 & 845 \\
\hline D143639 & 00010000000000000000000000000000 & 1 & 820 \\
\hline D143636 & 00001000000000000000000000000000 & 1 & 720 \\
\hline D143633 & 00001000000000000000000000000000 & 1 & 813 \\
\hline D143634 & 00001000000000000000000000000000 & 1 & 676 \\
\hline D143630 & 00000100000000000000000000000000 & 1 & 685 \\
\hline D143631 & 00000100000000000000000000000000 & 1 & 667 \\
\hline D143632 & 00000100000000000000000000000000 & 1 & 857 \\
\hline D143628 & 00000100010000000000000000000000 & 1 & 890 \\
\hline D145049 & 00000010000000000000000000000000 & 1 & 800 \\
\hline D145050 & 00000010000000000000000000000000 & 1 & 720 \\
\hline D145005 & 00000001000000000000000000000000 & 1 & 991 \\
\hline D145011 & 00000000100000000000000000000000 & 1 & 840 \\
\hline D145018 & 00000000100000000000000000000000 & 1 & 770 \\
\hline
\end{tabular}




\begin{tabular}{|c|c|c|c|}
\hline D145046 & 00000000100000000000000000000000 & 1 & 893 \\
\hline D145122 & 00000000010000000000000000000000 & 1 & 910 \\
\hline D145013 & 00000000010000000000000000000000 & 1 & 630 \\
\hline D145014 & 00000000010000000000000000000000 & 1 & 829 \\
\hline D145017 & 00000000010010000000000000000000 & 1 & 845 \\
\hline D145037 & 00000000010000000000000000000000 & 1 & 890 \\
\hline D145038 & 00000000010000000000000000000000 & 1 & 807 \\
\hline D145047 & 00000000010000000000000000000000 & 1 & 764 \\
\hline A155640 & 00000000010000000000000000000000 & 1 & 980 \\
\hline D145102 & 00000000010000000000000000000000 & 1 & 820 \\
\hline D145105 & 00000000010000000000000000000000 & 1 & 820 \\
\hline D145107 & 00000000010000000000000000000000 & 1 & 855 \\
\hline D145108 & 00000000010000000000000000000000 & 1 & 910 \\
\hline D145109 & 00000000010000000000000000000000 & 1 & 860 \\
\hline D145110 & 00000000010000000000000000000000 & 1 & 760 \\
\hline D145112 & 00000000010000000000000000000000 & 1 & 770 \\
\hline D145113 & 00000000010000000000000000000000 & 1 & 880 \\
\hline D145114 & 00000000010000100000000000000000 & 1 & 810 \\
\hline D145116 & 00000000010000000000000000000000 & 1 & 940 \\
\hline D145117 & 00000000010000000000000000000000 & 1 & 950 \\
\hline D145118 & 00000000010000000000000000000000 & 1 & 715 \\
\hline D145119 & 00000000010000000000000000000000 & 1 & 800 \\
\hline D145120 & 00000000010000000000000000000000 & 1 & 720 \\
\hline D145092 & 00000000010000000000000000000000 & 1 & 840 \\
\hline D145093 & 00000000010000000000000000000000 & 1 & 710 \\
\hline
\end{tabular}




\begin{tabular}{|c|c|c|c|}
\hline D145096 & 00000000010000000000000000000000 & 1 & 870 \\
\hline D145100 & 00000000010000000000000000000000 & 1 & 920 \\
\hline A155645 & 00000000010000000000000000000000 & 1 & 980 \\
\hline D145060 & 00000000010000000000000000000000 & 1 & 980 \\
\hline D145090 & 00000000010000000000000000000000 & 1 & 880 \\
\hline D145091 & 00000000010000000000000000000000 & 1 & 950 \\
\hline D145058 & 00000000010000000000000000000000 & 1 & 760 \\
\hline D145088 & 00000000010000000000000000000000 & 1 & 1020 \\
\hline D157795 & 00000000001000000000000000000000 & 1 & 955 \\
\hline D145004 & 00000000000010000000000000000000 & 1 & 700 \\
\hline D145032 & 00000000000001000000000000000000 & 1 & 880 \\
\hline D145027 & 00000000000001010000000000000000 & 1 & 815 \\
\hline D145063 & 00000000000001000000000000000000 & 1 & 935 \\
\hline D145026 & 00000000000000100000000000000000 & 1 & 790 \\
\hline D145069 & 00000000000000100000000000000000 & 1 & 790 \\
\hline D162164 & 00000000000000100000000000000000 & 1 & 750 \\
\hline D162165 & 00000000000000100000010000000000 & 1 & 700 \\
\hline D162177 & 00000000000000100000000000000000 & 1 & 1040 \\
\hline D162180 & 00000000000000100000000000000000 & 1 & 950 \\
\hline A158771 & 00000000000000010000000000000000 & 1 & 940 \\
\hline D145045 & 00000000000000010000000000000000 & 1 & 860 \\
\hline D145081 & 00000000000000010000000000000000 & 1 & 1020 \\
\hline D157787 & 00000000000000010000000000000000 & 1 & 840 \\
\hline D157788 & 00000000000000010000000000000000 & 1 & 680 \\
\hline D162171 & 00000000000000010000000000000000 & 1 & 750 \\
\hline
\end{tabular}




\begin{tabular}{|c|c|c|c|}
\hline D162172 & 00000000000000010000000000000000 & 1 & 570 \\
\hline D162173 & 00000000000000010000000000000000 & 1 & 615 \\
\hline D162174 & 00000000000000010000000000000000 & 1 & 620 \\
\hline D162175 & 00000000000000010000000000000000 & 1 & 610 \\
\hline D145054 & 00000000000000010000000000000000 & 1 & 820 \\
\hline D145062 & 00000000000000010000000000000000 & 1 & 850 \\
\hline A158754 & 00000000000000010000000000000000 & 1 & 960 \\
\hline A158769 & 00000000000000010000000010000000 & 1 & 930 \\
\hline D145033 & 00000000000000010000000000000000 & 1 & 625 \\
\hline D145035 & 00000000000000010000000000000000 & 1 & 874 \\
\hline D145059 & 00000000000000010000000000000000 & 1 & 730 \\
\hline D157798 & 00000000000000001000000000000000 & 1 & 995 \\
\hline D145044 & 00000000000000001000000000000000 & 1 & 840 \\
\hline D145003 & 00000000000000000100000000000000 & 1 & 995 \\
\hline D163648 & 00000000000000000000010000000000 & 1 & 800 \\
\hline D145070 & 00000000000000000000010000000000 & 1 & 960 \\
\hline D145006 & 00000000000000000000010000000000 & 1 & 920 \\
\hline D145040 & 00000000000000000000010000000000 & 1 & 650 \\
\hline D145085 & 00000000000000000000000000000100 & 1 & 800 \\
\hline D174082 & 00000000000000000000001000000000 & 1 & 1050 \\
\hline A160615 & 00000000000000000000000100000000 & 1 & 900 \\
\hline A160618 & 00000000000000000000000100000000 & 1 & 930 \\
\hline A160619 & 00000000000000000000000100000000 & 1 & 870 \\
\hline D175014 & 00000000000000000000000010000000 & 1 & 735 \\
\hline D177150 & 00000000000000000000000010000000 & 1 & 700 \\
\hline
\end{tabular}




\begin{tabular}{|c|c|c|c|}
\hline D177136 & 00000000000000000000000001000000 & 1 & 635 \\
\hline D177141 & 00000000000000000000000001000000 & 1 & 950 \\
\hline A164587 & 00000000000000000000000000010000 & 1 & 795 \\
\hline A164588 & 00000000000000000000000000010000 & 1 & 850 \\
\hline A164589 & 00000000000000000000000000010000 & 1 & 1050 \\
\hline A164593 & 00000000000000000000000000010000 & 1 & 900 \\
\hline D178275 & 00000000000000000000000000010000 & 1 & 865 \\
\hline D178282 & 00000000000000000000000000001000 & 1 & 860 \\
\hline A167951 & 00000000000000000000000000001000 & 1 & 875 \\
\hline A167952 & 00000000000000000000000000001000 & 1 & 875 \\
\hline A167953 & 00000000000000000000000000001000 & 1 & 975 \\
\hline A167955 & 00000000000000000000000000001000 & 1 & 940 \\
\hline A167965 & 00000000000000000000000000001000 & 1 & 820 \\
\hline D175006 & 00000000000001000000000000010100 & 1 & 840 \\
\hline D145012 & 00000000001000000000000000000000 & 1 & 895 \\
\hline D149288 & 00000010000000000000000000000000 & 1 & 845 \\
\hline A150011 & 00000010000000000000000000000000 & 1 & 790 \\
\hline A1504921 & 00000001000000000000000000000000 & 1 & 890 \\
\hline D145019 & 00000000000000010000000000000000 & 1 & 840 \\
\hline D145022 & 00000000000000000100000000000000 & 1 & 910 \\
\hline D145001 & 00000000000000000100000000000000 & 1 & 920 \\
\hline D145065 & 00000000000000000100000000000000 & 1 & 800 \\
\hline D145066 & 00000000000000000010000000000000 & 1 & 760 \\
\hline D145057 & 00000000000000000010000000000000 & 1 & 800 \\
\hline D145075 & 00000000000000000010000000000000 & 1 & 780 \\
\hline
\end{tabular}


Table A.3: Acoustic tagging capture history (ch) data, including the tag ID number, the weekly capture history, frequency and total length $(\mathrm{mm})$ at initial capture. This was used for the CJS model (so not set up as primary or secondary periods). A ' 1 ' denotes that a tagged individual was detected by a receiver during that week and a ' 0 ' denotes that an animal was detected by a receiver.

\begin{tabular}{cccc}
\hline \hline Tag ID & Capture History (Acoustic data) & Frequency & Total Length (mm) \\
\hline \hline ID25862 & 11111011111111100000000000000000000000000000000000 & 1 & 790 \\
ID25863 & 00011100111111001000101111111111111110011100000000 & 1 & 845 \\
ID25864 & 00000100011011000111111111111111111111111111111000 & 1 & 935 \\
ID25865 & 00000111110111111111111110011000000000000000000000 & 1 & 835 \\
ID25866 & 00000111110111111111111111111000000000000000000000 & 1 & 910 \\
ID25867 & 00000100001110111111100111111111110111110000000000 & 1 & 930 \\
ID25870 & 00000101111110111111011110110111101011100010100010 & 1 & 945 \\
\hline \hline
\end{tabular}


Table A.4: Robust design models fitted to the recapture data for pyjama sharks in Mossel Bay, used to estimate population size $(\mathrm{N})$, temporary emigration rates $\left(\gamma^{\prime \prime}, \gamma^{\prime}\right)$ and capture probability (p), the model rank, number of parameters (npar), AICc, delta AICc, model weight and model deviance. Best fit model in bold.

\begin{tabular}{|c|c|c|c|c|c|c|}
\hline model & Rank & npar & AICc & DeltaAICc & Model weight & Deviance \\
\hline$\varphi(\mathrm{TL}) \gamma^{\prime \prime}(0)=\gamma^{\prime}(0) p()=.c()$. & 1 & 8 & -0.9664 & 0.0000 & 0.28238 & -18.1277 \\
\hline$\varphi(.) \gamma^{\prime \prime}(0)=\gamma^{\prime}(0) p()=.c()$. & 2 & 7 & -0.8642 & 0.1023 & 0.26830 & -76.8411 \\
\hline$\varphi(\mathrm{TL}) \gamma^{\prime \prime}(.)^{-} \gamma^{\prime}(.) \mathrm{p}(.)^{-} \mathrm{c}()$. & 3 & 9 & 0.2984 & 1.2648 & 0.15003 & -19.1650 \\
\hline$\varphi(.) \gamma^{\prime \prime}()=.\gamma^{\prime}() p.()=.c()$. & 4 & 8 & 1.2027 & 2.1691 & 0.09546 & -77.0395 \\
\hline$\varphi(.) \gamma^{\prime \prime}(.) \gamma^{\prime}(.) \mathrm{p}()=.\mathrm{c}()$. & 5 & 9 & 2.4750 & 3.4415 & 0.05053 & -78.0693 \\
\hline$\varphi(t) \gamma^{\prime \prime}(0)=\gamma^{\prime}(0) p()=.c()$. & 6 & 10 & 2.6785 & 3.6449 & 0.04564 & -80.2057 \\
\hline$\varphi(\mathrm{TL}) \gamma^{\prime \prime}(.) \gamma^{\prime}(.) \mathrm{p}()=.\mathrm{c}()$. & 7 & 10 & 4.8149 & 5.7813 & 0.01568 & -16.9884 \\
\hline$\varphi(\mathrm{t}) \gamma^{\prime \prime}()=.\gamma^{\prime}(.) \mathrm{p}()=.\mathrm{c}()$. & 8 & 11 & 5.0570 & 6.0235 & 0.01389 & -80.2057 \\
\hline$\varphi(\mathrm{TL}) \gamma^{\prime \prime}(0)=\gamma^{\prime}(0) p($ season $)=c($ season $)$ & 9 & 11 & 5.1410 & 6.1074 & 0.01332 & -19.0408 \\
\hline$\varphi(.) \gamma^{\prime \prime}(0)-\gamma^{\prime}(0) p($ season $)-c($ season $)$ & 10 & 10 & 5.1453 & 6.1117 & 0.01330 & -77.7389 \\
\hline$\varphi(\mathrm{t}+\mathrm{TL}) \gamma^{\prime \prime}()=.\gamma^{\prime}(.) \mathrm{p}()=.\mathrm{c}()$. & 11 & 12 & 5.4472 & 6.4136 & 0.01143 & -21.1528 \\
\hline$\varphi(T L) \gamma^{\prime \prime}()=.\gamma^{\prime}() p.($ season $)=c($ season $)$ & 12 & 12 & 6.4973 & 7.4638 & 0.00676 & -20.1027 \\
\hline$\varphi(.) \gamma^{\prime \prime}(0)=\gamma^{\prime}(0) p($ session $)=c($ session $)$ & 13 & 11 & 7.2107 & 8.1772 & 0.00473 & -78.0520 \\
\hline$\varphi(.) \gamma^{\prime \prime}()=.\gamma^{\prime}() p.($ season $)=c$ (season) & 14 & 11 & 7.3116 & 8.2781 & 0.00450 & -77.9511 \\
\hline$\varphi(\mathrm{TL}) \gamma^{\prime \prime}(0)=\gamma^{\prime}(0) p($ session $)=c($ session $)$ & 15 & 12 & 7.4342 & 8.4007 & 0.00423 & -19.1658 \\
\hline$\varphi(\mathrm{t}) \gamma^{\prime \prime}(.) \gamma^{\prime}(.) \mathrm{p}()=.\mathrm{c}()$. & 16 & 12 & 7.4752 & 8.4417 & 0.00415 & -80.2057 \\
\hline$\varphi(\mathrm{t}+\mathrm{TL}) \gamma^{\prime \prime}(.) \gamma^{\prime}(.) \mathrm{p}()=.\mathrm{c}()$. & 17 & 13 & 7.9060 & 8.8725 & 0.00334 & -21.1528 \\
\hline$\varphi(.) \gamma^{\prime \prime}(.) \gamma^{\prime}() p.($ season $)=\mathrm{c}$ (season) & 18 & 12 & 8.6999 & 9.6663 & 0.00225 & -78.9810 \\
\hline$\varphi(t) \gamma^{\prime \prime}(0)=\gamma^{\prime}(0) p($ scason $)=c($ scason $)$ & 19 & 13 & 8.9688 & 9.9353 & 0.00197 & -81.1710 \\
\hline$\varphi(\mathrm{t}+\mathrm{TL}) \gamma^{\prime \prime}(0)=\gamma^{\prime}(0) p($ season $)=\mathrm{c}($ season $)$ & 20 & 14 & 9.4508 & 10.4172 & 0.00154 & -22.1085 \\
\hline$\varphi(.) \gamma^{\prime \prime}()=.\gamma^{\prime}() p.($ session $)=c($ session $)$ & 21 & 12 & 9.5998 & 10.5662 & 0.00143 & -78.0811 \\
\hline$\varphi(\mathrm{TL}) \gamma^{\prime \prime}(.)^{-} \gamma^{\prime}(.) \mathrm{p}($ session $)-\mathrm{c}($ session $)$ & 22 & 13 & 9.8455 & 10.8120 & 0.00127 & -19.2133 \\
\hline$\varphi(.) \gamma^{\prime \prime}(.) \gamma^{\prime}() p.($ session $)=\mathrm{c}($ session $)$ & 23 & 13 & 10.9504 & 11.9168 & 0.00073 & -79.1894 \\
\hline$\varphi(\mathrm{TL}) \gamma^{\prime \prime}(.) \gamma^{\prime}(.) \mathrm{p}($ season $)=\mathrm{c}($ season $)$ & 24 & 13 & 11.1587 & 12.1252 & 0.00066 & -17.9001 \\
\hline$\varphi(t) \gamma^{\prime \prime}()=.\gamma^{\prime}() p.($ season $)=c($ season $)$ & 25 & 14 & 11.4693 & 12.4357 & 0.00056 & -81.1710 \\
\hline
\end{tabular}




\begin{tabular}{|c|c|c|c|c|c|c|}
\hline$\varphi(t+T L) \gamma^{\prime \prime}()-.\gamma^{\prime}() p.($ season $)=c($ season $)$ & 26 & 15 & 11.9940 & 12.9605 & 0.00043 & -22.1085 \\
\hline$\varphi(t) \gamma^{\prime \prime}(0)=\gamma^{\prime}(0) p($ session $)=c($ session $)$ & 27 & 14 & 12.1422 & 13.1087 & 0.00040 & -80.4980 \\
\hline$\varphi(t+T L) \gamma^{\prime \prime}(0)=\gamma^{\prime}(0) p($ scssion $)=c($ scssion $)$ & 28 & 15 & 12.6013 & 13.5677 & 0.00032 & -21.5013 \\
\hline$\varphi(\mathrm{TL}) \gamma^{\prime \prime}(.) \gamma^{\prime}(.) \mathrm{p}($ session$)=\mathrm{c}($ session $)$ & 29 & 14 & 13.4523 & 14.4187 & 0.00021 & -18.1070 \\
\hline$\varphi(t) \gamma^{\prime \prime}(.) \gamma^{\prime}() p.($ season $)=c($ seeason $)$ & 30 & 15 & 14.0125 & 14.9790 & 0.00016 & -81.1710 \\
\hline$\varphi(\mathrm{t}+\mathrm{TL}) \gamma^{\prime \prime}(.) \gamma^{\prime}() p.($ season $)=\mathrm{c}($ season $)$ & 31 & 16 & 14.5811 & 15.5476 & 0.00012 & -22.1085 \\
\hline$\varphi(t) \gamma^{\prime \prime}()=.\gamma^{\prime}() p.($ session $)=c($ session $)$ & 32 & 15 & 14.6875 & 15.6539 & 0.00011 & -80.4960 \\
\hline$\varphi(\mathrm{t}+\mathrm{TL}) \gamma^{\prime \prime}(.)^{-} \gamma^{\prime}(.) \mathrm{p}(\text { session })^{-} \mathrm{c}($ session $)$ & 33 & 16 & 15.1882 & 16.1546 & 0.00009 & -21.5015 \\
\hline$\varphi(t) \gamma^{\prime \prime}(.) \gamma^{\prime}() p.($ session $)=c($ session $)$ & 34 & 16 & 17.2721 & 18.2385 & 0.00003 & -80.4985 \\
\hline$\varphi(t+T L) \gamma^{\prime \prime}(.) \gamma^{\prime}() p.($ session $)=c($ session $)$ & 35 & 17 & 17.8263 & 18.7928 & 0.00002 & -21.4954 \\
\hline$\varphi(\mathrm{t} \mid \mathrm{TL}) \gamma^{\prime \prime}(0)=\gamma^{\prime}(0) \mathrm{p}()=.\mathrm{c}()$. & 36 & 11 & 24.1818 & 25.1483 & 0.00000 & 0.0000 \\
\hline
\end{tabular}

$(p=$ apparent survival $\quad()=$. constant over time (i.e. not time-varying)

$\gamma^{\prime \prime}$ and $\gamma^{\prime}=$ temporary emigration paramet $\gamma^{\prime \prime}(.) \gamma^{\prime}()=$. Markovian emigration

$\mathrm{p}$ - probability of capture $\quad \gamma^{\prime \prime}()-.\gamma^{\prime}($.$) - random emigration model$

$\mathrm{c}=$ probability of recapture $\quad \gamma^{\prime \prime}(0)=\gamma^{\prime}(0)=$ zero emigration model

$(\mathrm{t})=$ varics by primary periods $($ timc-depe $\mathrm{p}(\mathrm{scssion})=\mathrm{p}$ varics by primary periods

$(\mathrm{t}+\mathrm{TL})=$ time-dependent with a total len; $\mathrm{p}($ season $)=\mathrm{p}$ varies by season

$(\mathrm{TL})=$ varies by length at first capture $\quad \mathrm{p}()=\mathrm{c}()$ indicates no capture response (i.e. captures \& recaptures are not influenced by tagging) 
Table A.5: CJS models fitted to the acoustic data used to obtain more robust estimates of apparent survival ( $\varphi$ ) for pyjama sharks in Mossel Bay), the model rank, number of parameters (npar), AICc, delta AICc, model weight and model deviance. Best fit model in bold.

\begin{tabular}{lcccccc}
\hline \hline \multicolumn{1}{c}{ Models } & Rank & npar & AICc & DeltaAICc & Model weight & Deviance \\
\hline \hline $\boldsymbol{\varphi}() p.($ Sex) & $\mathbf{1}$ & $\mathbf{3}$ & $\mathbf{2 7 6 . 5 2 7}$ & $\mathbf{0 . 0 0 0}$ & $\mathbf{0 . 1 9 9}$ & $\mathbf{2 6 1 . 0 2 6}$ \\
$\varphi(.) \mathrm{p}(\mathrm{TL}+\mathrm{Sex})$ & 2 & 4 & 276.838 & 0.311 & 0.170 & 268.608 \\
$\varphi(\mathrm{TL}) \mathrm{p}(\mathrm{Sex})$ & 3 & 4 & 277.212 & 0.685 & 0.141 & 268.983 \\
$\varphi(.) \mathrm{p}()$. & 4 & 2 & 277.378 & 0.851 & 0.130 & 263.946 \\
$\varphi(.) \mathrm{p}(\mathrm{TL})$ & 5 & 3 & 277.636 & 1.109 & 0.114 & 271.499 \\
$\varphi(\mathrm{TL}) \mathrm{p}()$. & 6 & 3 & 278.141 & 1.614 & 0.089 & 272.004 \\
$\varphi(\mathrm{TL}) \mathrm{p}(\mathrm{TL})$ & 7 & 4 & 278.323 & 1.796 & 0.081 & 270.093 \\
$\varphi(.) \mathrm{p}(\mathrm{TL} * \mathrm{Sex})$ & 8 & 5 & 278.480 & 1.953 & 0.075 & 268.133 \\
$\varphi(.) \mathrm{p}(\mathrm{t})$ & 9 & 50 & 364.826 & 88.299 & 0.000 & 215.618 \\
$\varphi(.) \mathrm{p}(\mathrm{t}+\mathrm{Sex})$ & 10 & 51 & 366.556 & 90.029 & 0.000 & 213.423 \\
$\varphi(\mathrm{TL}) \mathrm{p}(\mathrm{t})$ & 11 & 51 & 366.620 & 90.093 & 0.000 & 222.856 \\
$\varphi(\mathrm{t}) \mathrm{p}()$. & 12 & 50 & 382.517 & 105.990 & 0.000 & 233.309 \\
$\varphi(\mathrm{t}) \mathrm{p}(\mathrm{Sex})$ & 13 & 51 & 383.746 & 107.219 & 0.000 & 230.618 \\
$\varphi(\mathrm{t}) \mathrm{p}(\mathrm{TL})$ & 14 & 51 & 384.778 & 108.251 & 0.000 & 241.014 \\
$\varphi(\mathrm{t}) \mathrm{p}(\mathrm{t})$ & 15 & 98 & 638.757 & 362.230 & 0.000 & 190.843 \\
\hline \hline
\end{tabular}

$(\varphi)=$ survival

$\mathrm{p}=$ probability of capture

$(\mathrm{t})=$ time-varying

$()=$. constant over time (i.e. not time-varying)

Sex $=$ varies by sex

$(\mathrm{TL})=$ varies by total length

$(T L+\operatorname{Sex})=$ varies by total length with sex as an additive

$(\mathrm{TL} * \mathrm{Sex})=$ varies by a total length and sex interaction

$(\operatorname{Sex}+\mathrm{t})=$ varies by time with a sex additive 